Davie, S., Minto, C., Officer, R., Lordan, C. 2015. Defining value per unit effort in mixed métier fisheries. Fisheries Research, 165; 1-10.

\title{
Defining value per unit effort in mixed métier fisheries
}

Sarah Davie $^{\mathrm{a}^{*}}$, Cóilín Minto $^{\mathrm{b}}$, Rick Officer $^{\mathrm{b}}$, Colm Lordan $^{\mathrm{a}}$

\footnotetext{
${ }^{a}$ Fisheries and Ecosystem Advisory Services, Marine Institute, Oranmore, Galway, Ireland

${ }^{\mathrm{b}}$ Marine and Freshwater Research Centre, Galway-Mayo Institute of Technology, Dublin Road, Galway, Ireland

* Corresponding author: tel: +353 91 387200; fax: +35391 387201; email: sarah.davie@marine.ie
}

\begin{abstract}
Value achieved from time spent at sea is a central driver of fishing decisions and fishing behaviors. Value per unit effort (VPUE) is an important indicator of economic performance in itself and a useful metric within integrated mixed fisheries models. A time series of Irish first sale prices and total per trip landings values (VPT) highlight heterogeneity in fish prices and VPTs achieved by the Irish fleet spatially and temporally, as well as variability with species targeting. This investigation compared models to standardize fishing trip VPUE accounting for species targeting (métier groupings), engine power (a $\mathrm{kW}$ proxy for vessel size), seasonal and annual variability, fishing effort, and individual vessels (encompassing variability in vessel characteristics and skipper effects). Linear mixed effects models incorporating random vessel effects and within-group variance between métier groupings performed best at describing the variability in the dataset. All investigated factors were important in explaining variability, and thus important in standardizing VPUE. Models incorporating fishing days (days with reported fishing activity) and engine power as separate
\end{abstract}


variables resulted in improved AIC values. Therefore, fishing days were considered to be the most appropriate effort measure to generate VPUE. The effort unit traditionally applied in measures of per unit effort, fishing hours, performed comparatively poorly in relation to VPT.

\section{Key words}

Fish price; fishing value; value per unit effort; mixed effects models; temporal trends

\section{Introduction}

Maximizing the value returned from time spent at sea is an important imperative of commercial fishing operations, and a key driver of fishing decisions and behaviors. Value per unit effort (VPUE) is an important indicator of economic performance at various scales. Variation in the first sale landings price (also called ex-vessel prices - Sumaila et al., 2007; Swartz et al., 2013), can alter fisher's behavior (Marchal et al., 2007; Sumaila et al., 2007). The achievable price of a species or group of species will determine the level of investment fishers are prepared to make to catch it (Pinnegar et al., 2002), or whether they attempt to catch it at all (Bastardie et al., 2013). Fishers may adopt alternative strategies that are perceived to be more profitable given species prices and predicted catch value (Marchal et al., 2007).

Normal market drivers, i.e. supply, demand and quality determine price at first sale (Abernethy et al., 2010; Bastardie et al., 2013; Pinnegar et al., 2002). Previous research into price variability suggests that in many fisheries prices are relatively inelastic to supply and vice versa given by weak correlations between catch volume and achieved price (Swartz et al., 2013). Bastardie et al. (2013) also suggest that price more strongly influences fishermen than the prospect of large catch abundance. Fishermen preferentially target the Porcupine 
Bank $^{1}$ for larger Nephrops typically caught at lower landings per unit effort (LPUE) because of higher achievable market prices for the larger size grades (ICES, 2013).

The apparent economic importance of price may also be reflected in the total per trip landings value (VPT). It is therefore important to be able to compare the value achieved by individual fishing trips, however, VPT may be influenced by factors including trip duration, species (group) caught and retained, fishing grounds, or fishing season. Direct comparison between trips can therefore be misleading or inappropriate. Standardizing trip values to a 'per unit effort' (PUE) measure removes the influence of variable trip duration and takes account of price variations. Value per unit effort (VPUE) essentially incorporates economic factors into LPUE, reflecting the fisher's objective to maximize profit. At present, discarded catch has no economic value or cost to fishers, something which is likely to change under the upcoming implementation of the European common fisheries policy obligation to land all catches of commercial species. Under this new regulation, fishers will be required to land the volumes previously discarded and sold for non-human consumption at a nominal value (EC, 2013).

Whilst CPUE can be a good measure for variability in stock biomass, this is only appropriate if catchability remains constant (Gulland, 1983) and is not always the case (Campbell, 2004; Harley et al., 2001). It is widely acknowledged that processes introducing bias through varying catchability or availability must be accounted for to ensure proportionality between CPUE and total stock size. This is the underlying concept of standardizing catch rates (Campbell, 2004). Fluctuations in catchability and/or availability act to alter supply of fish. Whilst VPUE is an economic performance rather than proxy for abundance, changes in catchability or availability may similarly alter perceptions of CPUE and VPUE.

\footnotetext{
${ }^{1}$ A raised area $\sim 200 \mathrm{~m}$ deep between the Porcupine Seabight and Rockall Trough, approximately $110 \mathrm{mi}$ off the west coast of Ireland.
} 
A variety of factors influence catchability either directly or indirectly by changing the effectiveness of fishing effort (Maunder et al., 2006; van Oostenbrugge et al., 2002). These factors include gear/vessel attributes such as engine power (Rijnsdorp et al., 2000) or gross tonnage (Parente, 2004), increases in gear efficiency through technological innovation (van Oostenbrugge et al., 2002), age- or size-specific selectivity, gear saturation (Maunder et al., 2006), and fuel prices (Tidd, 2013). Other factors include skipper and/or crew skill (Mahévas et al., 2011), changes in seasonal and/or spatial distribution (Campbell, 2004; Mahévas et al., 2011; Tidd, 2013), the targeting behavior of a vessel (Maunder et al., 2006; Quirijns et al., 2008; Tidd, 2013), and management-induced responses (Maunder et al., 2006; Quirijns et al., 2008) such as quota restrictions. Whilst CPUE has been the primary scientific metric for biological stock assessment, VPUE is a more crucial metric for fishers. Fundamentally economic factors drive the decisions and behavior made by fishers whose primary objective is to optimize profit (Squires, 1987; Campbell, 2004).

Factors affecting the effort exerted by fishers, and the way effort is measured can also impact the PUE representation and its standardized forms (Borges et al., 2005; van Oostenbrugge et al., 2002). For example, it is important to ensure effort is accurately enumerated when using commercial CPUE data for stock assessment otherwise it may lead to bias or poor precision in the assessment (Tidd, 2013). Equally, accurate VPUE estimation must reflect the time taken to generate the value obtained to enable comparison among trips.

There is an increasing need to take such VPUE metrics into account within integrated management strategy evaluation models and decision support tools which aim to evaluate the costs and benefits of management measures. VPUE is an input in these models, driving the dynamics of simulated fleets, and an output, indicating the economic performance accruing to fishery segments. 
The aim of this study was to: a) model factors influencing total trip values achieved in the Irish fleet, b) produce standardized VPUEs, and c) facilitate direct comparison among trips. The analysis considers the relative influence of target species (métier groups), vessel engine power (in $\mathrm{kW}$ as a proxy for vessel size), season (encompassing changing stock availability), annual variability, trip duration (measured using different effort units), and vessel effects which encompasses both variation in vessel characteristics and skipper effects. The analysis generated two additional products: 1) a validated reconstruction of the first sale prices for species landed into Ireland (Euro per $\mathrm{kg}$ ), and 2) a time series of total first sale values achieved per trip (VPT; Euro).

\section{Materials and methods}

\subsection{Data}

The Irish fishing industry exploits a diverse range of species. The fleet consist of $\sim 400$ vessels $>10 \mathrm{~m}$ primarily operating in the waters around Ireland (ICES area VI and VII). Of these, round 23 larger pelagic vessels operate from the West African coast to northern Norway. There are an additional $\sim 650$ small vessels $(<10 \mathrm{~m})$ fishing inshore waters (these vessels are not considered in this analysis as completion of logbooks is not compulsory for vessels under $10 \mathrm{~m}$ in length). The majority of $\geq 10 \mathrm{~m}$ vessels are issued "polyvalent" national fishing licenses. These licenses allow operators a high degree of flexibility in terms of gear and target species. The most widely used gears include: mid-water pair trawls for targeting pelagic species, bottom otter trawls and beam trawls targeting bottom dwelling assemblages, and passive gears such as pots and gillnets. Pelagic fisheries generate the greatest landing volumes, while demersal fishing has the greatest number of vessel involved and can achieve higher catch values. Of particular importance, in value, are the high volumes of Nephrops 
landed. Landings from the $\geq 10 \mathrm{~m}$ fleet in 2011 were around 197 thousand tones, equating to a monetary value of approximately 222 million Euros at first sale.

All vessels $\geq 10 \mathrm{~m}$ in length, fishing in European waters on voyages longer than $24 \mathrm{~h}$ must complete a daily logbook of operations and a landing declaration upon return to port (EC, 1993). These records constitute the source of information for this investigation. Irish logbook data from 2004 to 2011 were made available from the Integrated Fisheries Information System (IFIS) database, provided by the Department of Agriculture, Food and the Marine (DAFM). The following data were retained for each fishing trip: landing date, fishing area (ICES division or subdivision), gear type, mesh size, landed weight raised to live weight (applying standard conversion factors when not landed whole), and species declared price per kilo.

The price achieved per kilo is linked to the presentation type (e.g. whole, gutted, filleted, tails) of the species when landed. Prices were scaled to the estimated live weight of landings (using the same conversion factors as above) to remove this variability. Exploratory analyses for each species, or group (e.g., Rajiformes), identified price ranges, distribution outliers, and the extent of missing values. The method of recording price appeared to change in 2008 from average value for a species within a port, to a traceable record method known as 'sales notes'. Under the 'sales notes' method, fish buyers are required to submit to DAFM the price and quantity at first sale by species for each consignment (this is mandated in various control and enforcement regulations; EC, 1993; 2008a; 2009). More dynamic price variations were observed since 2008 .

Missing prices for one or more species within a trip (20,269 records representing 3\% of price records) and outlier prices $(3,126 ;<0.5 \%)$ were filled in with average prices (fill-ins). Of these, trips containing $\geq 50 \%$ species fill-ins were removed from the analyses (4,112 trips) to prevent influencing visualized medians. Trips with less than $50 \%$ of species replaced were 
retained ( 8,779 trips; $7 \%$ of used dataset). The following algorithm was used to obtain the most accurate average price for use when replacing missing values:

Landing date, fishing division, landing port, species ID $^{2}$

Landing year, month, fishing division, landing port, species ID

Landing year, month, fishing division, species ID

Landing year, fishing division, species ID

Landing year, species ID

Landing year, higher species aggregation ${ }^{3}$

Trips associated with remaining unfilled prices were removed from the analysis ( 58 trips). The completed price database was used to calculate the value of each species landed $(\mathrm{kg}$ weight $\mathrm{x}$ price) within a fishing trip, then summed across species to give a total value per trip $(€)$. Prices were adjusted to account for inflation over the period applying the average annual Consumer Price Index (CPI) of Ireland ${ }^{4}$ to standardize prices to 2004 values.

Three effort measures were obtained from the logbooks on a per trip basis:

1. days at sea: the number of days a vessel was absent from port;

2. fishing days: number of days where fishing operations were reported within a trip; and

3. fishing hours: the time reported to have been spent fishing. As a quality control, reported instances of fishing hours exceeding $24 \mathrm{~h}$ were replaced with the maximum of $24 \mathrm{~h}$. Such instances occurred in $<2 \%$ of trips.

Each fishing trip was assigned to a métier according to classification rules described in Davie and Lordan (2011a) for otter trawls. Métiers were grouped into the following "métier groups" based on species aggregations to reduce overall complexity: Nephrops (Neph),

\footnotetext{
${ }^{2}$ Based on FAO's ASFIS List of Species 3alpha code ( last visited 11/04/2013)

${ }^{3}$ Common name/group e.g. monkfish (Lophius spp and Lophius Piscatorius) and rays (Raja clavata, Leucoraja fullonica, Raja brachyura, Raja montagui, Leucoraja naevus, Amblyraja radiata, Raja undulata, Rajiformes, Raja fyllae, Raja spp)

${ }^{4}$ CPI obtained from the Central Statistics Office of Ireland: http://www.cso.ie (last visited 7/11/2014)
} 
demersal (Dem), pelagic (Pel), slope (Slope), deepwater (Deep), other trawl (OT). Gear categories were used for all other gear types: Scottish seiner (SSC), beam trawl (TBB), dredges (DRB), gillnets (Nets), pots and traps (Pots), longlines (Hooks). It is possible for vessels to switch métier groups on a trip by trip basis. On average, vessels carry out fishing trips within two métier groups per year, but this can vary between 1 and 7 .

A total of 127,067 fishing trips were available between 2004 and 2011 for analysis. Table 1 gives an overview of the data. A small number of trips occurring early in the time series were assigned to the Deep métier group (144 trips), the result of a declining fishery. This métier group was excluded from the modeling processes due to absence of data across the whole period. Trips (4) carried out by the single largest Irish vessel (having an engine size $>2500 \mathrm{kw}$ greater than the next largest vessel) were removed to aid model fitting, particularly in relation to inclusion of kilowatt effort. Comparison fits with and without these trips showed minimal change to estimated coefficients.

\subsection{Modeling}

The goal of modeling was to explore factors which may explain variability in total per trip landings values such as effort, year, species targeting, and seasonal effects. As an initial starting point a linear model ( $l m$ function within the stats package; R core team, 2014) was fitted to the total value achieved per trip accounting for year, métier group, season and the two way interactions (model statements in Table S1). It was not possible to include the three way interaction among the main effects due to a lack of hook observations within a small number of combinations.

The model was expanded to include an effort variable to increase variation explained. Effort was included both as a variable with a free parameter and as an offset where the parameter is fixed at one (Table S1). Separate effort and engine power variables and the effort offset combination equivalents were fitted to explicitly account for vessel power as a 
proxy for variability on vessel size. The interaction between the effort measure and engine power was also fitted along with the equivalent offset combinations (Table S1).

Examination of the fit diagnostics revealed over-dispersed residuals for all models indicated by "heavy" tails on the Q-Q plots. Comparison of the residual distribution to a random normal distribution showed some alignment, although residuals tended to be narrower and taller than a single normal distribution. The over-dispersed pattern within the tails of the residual distribution could have resulted from vessel effects, suggesting some fishers performed better than others. To test this theory, a series of linear mixed effects models (Pineheiro and Bates, 2000; Singer, 1998) were applied using the nlme package in R (Pineheiro et al., 2014). The mixed effects model allows the use of both fixed and random effects within the same analysis. The first of these models applied fishing days and engine power separately with a random vessel effect $\left(\beta_{1, V_{i}}\right.$; Table S1). The second model replaced the two independent variables (power and effort) and their associated interactions with a single 'capacity effort' variable (kilowatt fishing days and kilowatt days at sea). In further investigations, the mixed effects model was expanded to include capacity effort, and the influence of year on vessel random effects. Nesting of random vessel effects within métier group was also fitted (Table S1). This allowed vessel error terms to be correlated and also allowed correlation of métier group error terms.

These model formulations again resulted in over-dispersion of the residuals, although the severity was reduced. Differences in the residual variances among métier groups were investigated through $N\left(0, \sigma_{M_{i}}^{2}\right)$ as an alternative cause of the observed over-dispersion given some métier groupings contained a greater level of variation in VPT. From these models (lme.kwfd and lme.fd; Table 2) the importance of interactions were tested by comparing AIC values of the re-fitted model with formulations that excluded interaction terms. Hausman 
tests were performed following Greene (2012) to test the independence of random effects and continuous covariates.

To further account for the persistent heavy tails observed during model fitting, the function heavyLme in R package heavy (Osorio, 2014) was applied to the two best fitting models (Table 2). This function applies a linear mixed-effects model under a heavy-tailed distribution, essentially allowing for an underlying mixed distribution. Residual variances of these models are given as $(1-p) N\left(0, \sigma^{2}\right)+p t_{v}(0)$ where $p$ is the contaminating proportion and $t_{v}(0)$ is a zero mean $t$-distribution with $v$ degrees of freedom.

\section{Results}

\subsection{Visualization}

Prices at first sale for species (groups) landed by the Irish fleet vary in response to factors including time, métier, area caught, and the landing port. Many species show annual and inter-annual fluctuations over the period analyzed, as well as variations among métiers and areas. Nephrops, for example, show relatively stable prices in ICES areas VIIa, VIIg and VIIj as well as VIIb within the Nephrops métier (Figure 1). However there were large fluctuations over the earlier period from the slope métier in VIIb, and within métiers operating in VIIc and VIIk, which can be linked to the Porcupine Bank Nephrops fishery. These prices became more stable, at a reduced level after 2008. Stability reflects two aspects, establishment of this relatively new Porcupine Bank fishery, in combination with the greater certainty arising from traceable documentation associated with the introduction of sales notes. Observed reductions in price coincide with reduced demand at the onset of the Irish economic downturn.

Underlying trends achieved VPTs are identified both within and between métier groups as illustrated by the 'métier group' box-plots of VPT (natural log transformed for comparison) (Figure 2), although individual VPTs are highly variable. Pelagic trips achieve higher trip 
values than other métier groups. Dredges (DRB) demonstrate a distinct declining trend in trip value and decreased trip variation. Hook trips drop in value after 2006, whilst Scottish seines (SSC) and beam trawls (TBB) indicate small value increases from 2004 to 2011. Other métiers such as Nephrops (Neph) and other otter trawls (Ot) appear more constant. Several métiers (e.g. Dem, TBB) show reduced trip value during the 2009-2010 seasons, a time when Ireland was in recession.

Seasonal patterns of métier groups are highlighted by visualizing monthly average trip values (Figure 3). Two distinct patterns are observed, those demonstrating higher value trips in summer months (e.g. Dem, SSC, and Neph), and those with more valuable trips over winter months (Slope, Pel, Pots, and Nets). The Nephrops group attained higher average values during the summer months, although seasonal variation reduced over time. Average 2011 trip values were some of the highest across the period. The seasonal low winter average values continue throughout the period for Dem and are more pronounced in 2010-11. Scottish seiners follow the same seasonal pattern, 2009 was pronounced after which average trip values increased. Trip value of this métier did not decline around 2009 as those within the Nephrops and demersal métiers did. Beam trawl values were quite variable, although a general increase in trip value occurred in the latter half of 2010, and early 2011. Seasonality is unclear within this group. Dredging (DRB) values dropped suddenly and substantially from the start of 2006. These declines result from decreased per kilo prices of scallops in particular. Monthly average trip values are variable, although slightly higher summer values were observed.

Lower average trip values occurred within the slope métier during summer months, particularly between 2007 and 2009. In contrast, some of the highest summer trip values were achieved in 2010 followed by particularly valuable trips at the start of 2011 . The other otter trawl métier (Ot) typically demonstrated increased VPT in winter months experienced 
particularly high values during the winter of 2007/08. Average trip values achieved by the pelagic group increased after 2005, distinguished by disparity between high value winters and low summer values. High per kilo values for herring (2005-2007), combined with a peak in mackerel prices in 2007 resulted in particularly high VPTs in winter 2006/07. Such high average value winter trips became less apparent after 2009 in conjunction with increased summer trip values. The pots métier attained higher average winter values. The scale of fluctuations within the group declined after 2008 with the deterioration in crab and whelk prices.

\subsection{Modeling}

\subsubsection{Development}

The initial linear model of total value achieved per trip accounting for year, métier group, and seasonal effects explained a relatively small proportion of the variance $\left(\mathrm{R}^{2}=43 \%, p\right.$-value $<2.2 \mathrm{e}-16,126781$ residual degrees of freedom). The AIC values (Akaike, 1974) declined upon incorporation of an effort measure variable (Table S1). Offsetting effort did not improve the model fit. Of the effort measures tested, fishing effort in hours was shown to be the lest appropriate effort measure, when compared to sea days and fishing days, the latter of which produced the best fits. Lower AIC values were achieved for models in which engine power was explicitly accounted for independent to the effort measure than when using the capacity effort $(\mathrm{kW})$ equivalents. This occurred for models with and without an interaction between effort measure and engine power.

Mixed effects models applied as an alternative to simple linear models gave better AIC value fits to the data, particularly when vessel was included as a random effect. The Hausman tests on the final lme.fd model rejected the null hypothesis of independence between the random effects and continuous covariates, though negative variances of the differences in the 
coefficients highlight concerns with over-interpreting the test statistic. Further development of random effects indicated comparatively minor fit improvements. The most complex of these trials, incorporating year and kilowatt fishing days into random vessels effects, led to the lowest AIC value. However, the degrees of freedom increased significantly reflecting the increased complexity of the model suggesting overfitting. Nesting of random effects, namely vessels within métier groups, reduced the degrees of freedom. However, the appropriateness of applying nesting is not certain especially given an increase in AIC value. The presence of over-dispersion in the residuals remained.

Shifting to an error distribution differing by métier group had little effect on the mean parameter estimates (unsurprising given the number of observations). Rather, it affected their standard errors, resulting in less conservative estimations of uncertainty. Application of a student t-distribution to the underlying error distribution of the liner mixed effects model accounting for the observed heavy-tailed distribution improved the overall model fit, however was computationally demanding ( $36 \mathrm{~h}$ to fit).

\subsubsection{Model selection}

The coefficient representing effort was examined across the four best performing models (lme.fd, lme.kwfd, heavy.fd, and heavy.kwfd; Table 2), based on AIC value, degrees of freedom, and the level of over-dispersion. This coefficient allows for non-proportionality between value and effort. Values deviating from one imply elasticity, whereas coefficients close to unity imply proportionality (allowing direct division of VPT by effort when considering the other variable attributes included in the model). This coefficient varied from 1.038 to 1.171 among models (Table 2). Models with separate fishing days and engine power terms resulted in higher coefficients for fishing days than those with capacity fishing days. Effort coefficients generated from the application of the contaminated distribution (heavy.kwfd and heavy.fd) led to higher values. Of these models, lme.fd was considered the 
most appropriate for use in standardizing VPUE due to the combination of AIC value, close unity of effort coefficient (1.038), and computational ease. Significance of the interactions between variables for this model are detailed in Table 3. Individual coefficient values are provided in supplementary information Table S2.

The lme.fd model was applied to an average powered Scottish seine vessel $(368 \mathrm{~kW})$ actively fishing four days during a trip to demonstrate the variability of value per trip across the annual and seasonal variables (Figure 4) from which an increase in trip value is apparent over time.

\section{Discussion}

VPUE indices as derived here have a widespread application within fisheries assessment and management, including vessel and fleet level performance indicators. Here we discuss the progression from data interrogation to the derivation and estimation of model standardization, concluding with a summary of real management applications of VPUE indices.

\subsection{First sale price and value}

This investigation presents, for the first time, a time series for first sale prices and total landings value per trip for Irish fisheries. The two time series highlighted heterogeneity in prices and values achieved by the Irish fleet spatially and temporally, and also the variation between métier groupings. Reflection of such variability in the distribution of effort over space and time was also observed by Bastardie et al. (2013) in the Danish fleets.

Nephrops was presented here as a clear example of observed changes in first sale prices. Large sized Nephrops landed from the Porcupine Bank fishery (primarily within ICES divisions VIIc and VIIk; ICES, 2012) in earlier years consistently achieved higher per kilo prices than the smaller individuals of Irish Sea fisheries. Prices dropped in this fishery after 2008 to levels more consistent with other Nephrops fisheries following reduced market 
demand at the onset of an economic downturn, combined with an excess of Nephrops in frozen storage.

Irish pelagic species typically have comparatively lower first value prices than most demersal species. However, pelagic fisheries obtain the highest per trip values. This observation is consistent with the findings of Sethi et al. (2010) on global fisheries developments. Sethi et al. (2010) noted since 1950 the species preferentially targeted by fishers have been those with high profit potential attributes, i.e. those with high catch biomass or those inhabiting shallow, obtainable habitats. In the Irish context, the pelagic fisheries represent the highest catch biomass. Bastardie et al. (2013) found that the decision to go fishing for larger vessels, associated with pelagic fleets, was also highly influenced by fish prices. These findings reiterate the importance of economic drivers of fishing behaviors.

\subsection{Modeling VPUE}

A mixed effects linear model with within-group variability (lme.fd) was chosen as the most appropriate model to standardize VPUE from fishing trip total landings values, enabling direct comparison among fishing trips. Using the Cobb-Douglas log-log function (Cobb and Douglas, 1928) within the model allowed several variables known to impact catch rates (fishing effort, engine power $(\mathrm{kW})$, métier grouping, and season, along with a year effect) to be incorporated while treating individual vessels as random effects. The log-log form has an aspect of "constant rate of substitution", whereby the same revenues can be produced by having $\beta_{\mathrm{z}}$ more fishing days and $\beta_{1}$ less power, substituting each other at rate of $-\frac{\beta_{1}}{\beta_{2}}$. In this application, such substitutions are possible, an advantage of this approach. Alternative formulations could have been applied such as the translog form (Christensen et al., 1973) which is considered to be more flexible, especially in economic applications (see Hoff, 2004 for an example). The added complexity was considered to be unnecessary for this application. 
Several previous studies into the standardization of catch and effort data have utilized random effects for vessel and for vessel and year interactions whilst examining fishing power (Bishop et al. 2004; Helser et al. 2004). Random vessel effects were explored to account for between-vessel variability. This allows for variation in catchability resulting from individual characteristics between vessels not explicitly accounted for elsewhere within the models. Incorporating both vessel and year as random effects accounts for vessel variation over time due to increased engine power or technological capability, and human effects (Mahévas et al., 2011; Marchal et al., 2007). Individual fisher performance will differ due to varying efficiency in "foraging behavior", and varying levels of skipper knowledge or gear experience. More recently, Tidd (2013) included vessel random effects to explain variance in landings per unit effort associated with gear, seasonal and area effects as well as variation in efficiency and capacity. Tidd (2013) considered that ignoring vessel effects could have produced negatively biased LPUE estimates.

This investigation tested both vessel and the interaction between vessel and year as random effects, along with the time spent fishing. The inclusion of vessel as a random effect within the model resulted in a large reduction in AIC, implying a large variation between individual vessels in their ability to generate value from a trip. Inclusion of vessel as a random effect essentially incorporates a number of factors which differ between vessels but are not explicitly accounted for as parameters within the model, or which are not freely available for inclusion as individual variables. This includes factors such as skipper and/or crew experience (Mahévas et al., 2011; Marchal et al., 2007) and individual economic circumstances. In addition, the random vessel effect encompasses variation in physical vessel characteristics such as gross tonnage or breadth which have shown to be important in other studies (e.g. Hoff, 2004; Parente, 2004). Here, inclusion of additional random effects reduced the AIC, although the reduction was not as pronounced as the inclusion of vessel. This may 
relate to the low likelihood of vessels having markedly increased power or efficiency during the relatively short time series examined.

An alternative style of modeling random effects was the nesting of variables. Several combinations were tested, including nesting vessels by métier group (leading to a higher AIC value). The appropriateness of nesting is questionable given the capacity of vessels to switch between métiers from trip to trip. A crossed random effects analysis would be required to account for this type of nesting. This investigation limited métiers as fixed effects due to the unchanging, limited number of potential métiers (11), while vessels and their associated attributes are able to change throughout the analysis. Interest was in their main effects, and not just the métier level variability.

Whilst a wide variety of vessel characteristics could influence PUE measures, several have been found to have little or no influence on CPUE (Parente, 2004). This study focused on data which are freely, and consistently available across the Irish fleet. In relation to vessel characteristics, this was restricted to engine power, shown to be an important characteristic by Parente (2004) and Hoff (2004). Whilst vessel length was also available, this characteristic is highly correlated with engine power (Davie et al., 2014). In formulation of PUE indices, collinearity between main effects variables should be avoided, to reduce the risk of model fitting becoming numerically unstable or over-fitted (Maunder and Punt, 2004).

The fixed effects of the final model included year, métier group, engine power, season and fishing days. Year was used to account for underlying variation in species availability (stock size was shown to be an important descriptor in estimating trip value in Danish trawl vessels; Hoff, 2004), and for annual variation in first sale prices which would result in variation in per trip values.

Considerable variation in VPUE was identified among métier groups, highlighted by between-métier variation within the residual error. This is consistent with the results of 
previous LPUE analyses that detected significant differences in fishing power related to targeting behaviors (Mahévas et al., 2011; Quirijns et al., 2008). In this study, the greater variance in VPUE, and larger number of negative residuals for the pelagic métier generated much of the inflated negative tail observed in the overall residual distribution. These results may result from under-reporting of catches on trips, consequently reducing reported values obtained. However, given the typically single species nature of pelagic fisheries (Davie and Lordan, 2011a), variability in prices between species may better explain these differences. Alternatively differences in fisher behavior between the pelagic and other métiers could plausibly result from differences in fishing practice. Pelagic fishers can scout, acoustically searching for particular shoals to target (Cosgrove et al., 2014). Such specific targeting is not possible in other métiers, and more time is spent with nets in the water over a greater number of days before returning.

The incorporation, and importance, of the seasonal proxy quarter reflected known a priori seasonality within the Irish fleet, including the winter peaks in pelagic fisheries, and summer peaks in Nephrops targeting (Davie and Lordan, 2011a). In other studies, seasonal proxies or spatial areas were explicitly included (e.g. Mahévas et al. 2011). An amount of spatial variation in fisher behavior is inherently incorporated by accounting for targeting behavior through broad métier groups. The different otter trawl métier groups of pelagic, demersal, Nephrops and slope typically cover different fishing grounds (unpublished data from VMS data linked to métiers defined in Davie and Lordan (2011a) and Gerritsen et al. (2012)). Quirijns et al. (2008) identified only modest inter-annual variations in micro-spatial indices and concluded that bias introduced by not explicitly accounting for such micro-scale variation in targeting would not significantly affect CPUE. Including a fine resolution spatial dimension to this type analysis is technically possibly with availability of VMS-linked logbook data. However, vessels often move between patches even during fishing trips and 
this added complexity is beyond the scope of what is possible within a generic fleet level study such as this.

Through model explorations fishing days were determined to be the most appropriate effort measure to apply when calculating Irish value per unit effort (three effort metrics were explored; fishing days, fishing hours, days-at-sea, and their capacity equivalents; kW days, $\mathrm{kW}$ hours and $\mathrm{kW}$ days-at-sea). Fishing days represents the number of days on which fishing operations were reported within logbooks. Evaluation of effort and engine power as separate variables was found to result in better model fits than their capacity effort counterparts (indicated by lower AIC value). The inclusion of engine power within the model helps to account for efficiency changes which could cause interpretation biases in long-term trends. The effort measure coefficient was slightly lower when effort and engine power were included separately, a value of 1.038 compared to 1.047. A coefficient value of 1 would validate a direct division of per trip value by the effort measure given a set of modeled terms. The coefficient values obtained here (1.038-1.171), however, imply faster than proportional growth between aggregate value and effort. In a single species scenario the effort coefficient is an amalgamation of the price elasticity and exponent for effort in a catch model, which should have a value less than or equal to one. Changes in catchability and biomass likely effect the estimated coefficient but these should be somewhat mitigated by the inclusion of year and quarter effects. The finding that the coefficient is greater than one could therefore result from: a breakdown in the price elasticity, where price over the time period may be governed by dynamics external to the system; or the mixed fisheries aspect where price elasticizes hold for a single species but where multiple species of different prices are caught, the aggregate has an altered effort coefficient.

Days at sea effort and capacity units are often used in effort management regulations such as those effected for cod recovery within the Irish Sea and West of Scotland since 2003 
(Davie and Lordan, 2011b; EC, 2002; 2003; 2004; 2008b). The time reported actually spent fishing (fishing hours) has traditionally been used as the effort measure in the computation of per unit effort, including as the standard input for the calculation of commercial catch or landings per unit effort indices used to tune stock assessments (ICES, 2012). Fishing hours are also used as an auxiliary variable in raising discards to fleet and fishery level (Allain et al., 2003; Borges et al. 2005). Tidd (2013) used fishing hours for nominal vessel landing rates (LPUE) believing, as was thought here, that management decisions based on effort measured in hours would provide a less crude measure which closely relates to actual fishing activity. Given this history we had expected fishing hours to outperform other effort units in the formulation of VPUE. This however was not the case. A possible explanation for the poorer performance of fishing hours in this investigation could be the inaccurate recording of hours within the logbooks. Finding fishing hours to be the poorest effort measure in calculating VPUE was unexpected however, the application of fishing days as a more appropriate alternative effort measure appears to be logical. It is unlikely that fishers make fishing decisions on an hourly basis, and rather more likely operate on a daily basis. Value is only generated on days when fishing operations occur, as strictly speaking steaming days do not generate revenue as fishing activity does not occur. In a broader sense however, steaming days could be considered to generate revenue if moving to alternative grounds with higher value catches.

\subsection{Conclusions}

Variable fisher behavior here considered as random vessel effects leads to variation in the values and effective effort obtained between trips. Tidd (2013) notes managers applying effort limitation need to be aware of the variability in catchability among individual fishers operating within fisheries that utilize the same stock. This is especially relevant within mixed fisheries where market conditions, fishing costs, and management regimes alter fisher 
targeting behavior (Quirijns et al., 2008). For management to be more effective in reducing fishing mortality, attention should be shifted from nominal effort to consider the factors which contribute to effective effort. Properly accounting for variability in vessel characteristics, targeting, seasonal, and area effects should result in improved effort management (Tidd, 2013).

The model developed here is empirical and cannot account for possible changes in behavior of fishers beyond the main effects to which it has been conditioned. The model provides parameters to condition the VPT for the formulation of a VPUE index rather than providing any predictive capability to changing behavior. Whilst the main effects of VPUE are unlikely to change, the relationship between VPT and effort may alter as vessels reoptimize inputs in response to shifting economic pressures. Such alterations may result from differing approaches to management from the current quota based policy (for example, adoption of effort-based schemes that limit fishing time, adoption of closed areas, or marked changes in fuel prices). However, in such cases, the model presented could be re-run including the change as a pre- and post- variable to determine influence on the VPUE relationship.

Generation of standardized price at first sale, value per trip and VPUE all have applications as economic performance metrics within management plans, and as input and output variables for large scale, integrated bioeconomic fisheries models, potentially providing measures for effort allocation and indicators of economic outcomes. Indeed, VPUE is already in use within bio-economical modeling as a driver of fisher behavior as a proxy of "revenue" (e.g. Tidd et al., 2012).

Future developments could generate spatially explicit maps of VPUE to inform spatial management, and allow identification of areas with minimal economic impact. Such mapping could also benefit fishers by identifying areas of high value. Such extensions could 
operationalize incentivized management systems for responsible fishing e.g. real time credit system proposed by Kraak et al. (2012). Alternatively, VPUE might be viewed by managers as an indicator of the health of an area, by tracking the profitability of fishing. Applying a profit maximizing assumption to fisher behavior (increasingly acknowledged in fisher behavior models, see van Putten et al. (2012) for recent review), could result in interpretation of variability and fluctuations in VPUE as resulting from changes in the underlying stock availability.

\section{Acknowledgements}

The authors would like to thank the Irish Department of Agriculture, Food and the Marine for providing logbook information. Thanks to Hans Gerritsen for his advice and guidance on visualizing price information, as well as the anonymous reviewers for their help in improving this manuscript. This study was supported by the EU European Regional Development Fund (ERDF) through Atlantic Area Program funding of the GEPETO project. Authorship sequence reflects levels of contribution through the "sequence-determines-credit approach". Author contributions: data configuration: SD; data analyses: SD, CM; manuscript: SD, RO, CM, CL.

\section{References}

Abernethy, K.E., Trebilcock, P., Kebede, B., Allison, E.H., Dulvy, N.K., 2010. Fuelling the decline in UK fishing communities? ICES J. Mar. Sci. 67, 1076-1085.

Akaike, H. 1974. A new look at the statistical model identification. IEEE Trans. Autom. Control. 19, 716-723. 
Allain, V., Biseau, A., Kergoat, B. 2003. Preliminary estimates of French deepwater fishery discards in the Northeast Atlantic Ocean. Fish. Res. 60, 185-192.

Bastardie, F., Nielsen, J.R., Andersen, B.S., Eigaard, O.R. 2013. Integrating individual trip planning in energy efficiency - building decision tree models for Danish fisheries. Fish. Res. 143, 119-130.

Bishop, J., Venables, W.N., Wang, Y.G. 2004. Analysing commercial catch and effort data from a penaeid trawl fishery. A comparison of linear models, mixed models, and generalized estimating equations approaches. Fish. Res. 70, 179-193.

Borges, L., Zuur, A., Rogan, E., Officer, R. 2005. Choosing the best sampling unit and auxiliary variable for discards estimations. Fish. Res. 75, 29-39.

Campbell, R. A. 2004. CPUE standardisation and the construction of indices of stock abundance in a spatially varying fishery using general linear models. Fish. Res. 70, 209227.

Christensen, L.R., Jorgenson, D.W., Lau, L.J. 1973. Transcendental logarithmic production frontiers. Rev. Econ. Stat. 55, 28-45.

Cobb, C.W., Douglas, P. H. 1928. A theory of production. Am. Econ. Rev. 18 (Supplement), $139-165$.

Cosgrove, R., Sheridan, M., Minto, C., Officer, R. 2014. Application of finite mixture models to catch rate standardization better represents data distribution and fleet behavior. Fish. Res. 153, 83-88.

Davie, S., Lordan, C. 2011a. Definition, dynamics and stability of métiers in the Irish otter trawl fleet. Fish. Res. 111, 145-158.

Davie, S., Lordan, C. 2011b. Examining changes in Irish fishing practices in response to the cod long-term plan. ICES J. Mar. Sci. 68, 1638-1646. 
Davie, S., Minto, C., Officer, R., Lordan, C., Jackson, E. 2014. Modeling fuel consumption of fishing vessels for predictive use. ICES J. Mar. Sci. doi:10.1093/icesjms/fsu084

EC. 1993. Council Regulation (EEC) No 2847/93 of 12 October 1993 establishing a control system applicable to the common fisheries policy. Off. J. Eur. Union. L261, 1-16.

EC. 2002. Council Regulation (EC) No 2341/2002 of 20 December 2002 fixing for 2003 the fishing opportunities and associated conditions for certain fish stocks and groups of fish stocks, applicable in community waters and, for community vessels, in waters where catch limitations are required. Off. J. Eur. Union. L356, 12-120.

EC. 2003. Council Regulation (EC) No 2287/2003 of 19 December 2003 fixing for 2004 the fishing opportunities and associated conditions for certain fish stocks and groups of fish stocks, applicable in community waters and, for community vessels, in waters where catch limitations are required. Off. J. Eur. Union. L344, 1-119.

EC. 2004. Council Regulation (EC) No 423/2004 of 26 February 2004 establishing measures for the recovery of cod stocks. Off. J. Eur. Union. L70, 8-11.

EC. 2008a. Commission Regulation (EC) No 1077/2008 of 3 November 2008 laying down detailed rules for the implementation of Council Regulation (EC) No 1966/2006 on electronic recording and reporting of fishing activities and on means of remote sensing and repealing Regulation (EC) No 1566/2007. Off. J. Eur. Union. L295, 3-23.

EC. 2008b. Council Regulation (EC) No 1342/2008 of 18 December 2008 establishing a long-term plan for cod stocks and the fisheries exploiting those stocks and repealing Regulation (EC) No 423/ 2004. Off. J. Eur. Union. L348, 20-33.

EC. 2009. Council Regulation (EC) No 1224/2009 of 20 November 2009 establishing a Community control system for ensuring compliance with the rules of the common fisheries policy, amending Regulations (EC) No 847/96, (EC) No 2371/2002, (EC) No 811/2004, (EC) No 768/2005, (EC) No 2115/2005, (EC) No 2166/2005, (EC) No 
388/2006, (EC) No 509/2007, (EC) No 676/2007, (EC) No 1098/2007, (EC) No 1300/2008, (EC) No 1342/2008 and repealing Regulations (EEC) No 2847/93, (EC) No 1627/94 and (EC) No 1966/2006. Off. J. Eur. Union. L343, 1-50.

EC. 2013. Council Regulation (EU) No. 1380/2013 of the European Parliament and of the Council of 11 December 2013 on the Common Fisheries Policy, amending Council Regulations (EC) No 1954/2003 and (EC) No 1224/2009 and repealing Council Regulations (EC) No 2371/2002 and (EC) No 639/2004 and Council Decision 2004/585/EC. Off. J. Eur. Union. L354: 22-61.

Greene, W.H. 2012. Econometric Analysis. Prentice Hall, New Jersey.

Gerritsen, H.D., Lordan, C., Minto, C., Kraak, S.B.M. 2012. Spatial patterns in the retained catch composition of Irish demersal otter trawlers: High-resolution fisheries data as a management tool. Fish. Res. 129-130, 127-136.

Gulland, J.A. 1983. Fish Stock Assessment: A Manual of Basic Methods. Wiley, Chichester. Harley, A.J., Myers, R.A., Dunn, A. 2001. Is catch-per-unit-effort proportional to abundance. Can. J. Fish. Aquat. Sci. 58, 1760-1772.

Helser, T.E., Punt, A.E., Methot, R.D. 2004. A generalized linear mixed model analysis of a multi-vessel fishery resource survey. Fish. Res. 70, 251-264.

Hoff, A. 2004. The linear approximation of the CES function with $n$ input variables. Mar. Resour. Econ. 19, 295-306.

ICES. 2012. Report of the Working Group for the Celtic Seas Ecoregion (WGCSE), 9-18 May 2012, Copenhagen, Denmark. ICES CM 2012/ACOM:12.

ICES. 2013. Report of the Benchmark Workshop on Nephrops Stocks (WKNEPH), 25 February-1 March 2013, Lysekil, Sweden. ICES CM 2013/ACOM:45.

Kraak, S.B.M., Reid, D., Gerritsen, H., Kelly, C., Fitzpatrick, M., Codling, E.A., Rogan, E. 2012. 21st century fisheries management: a spatio-temporally explicit tariff-based 
approach combining multiple drivers and incentivising responsible fishing. ICES J. Mar. Sci. 69, 590-601.

Mahévas, S., Vermard, Y., Hutton, T., Iriondo, A., Jadaud, A., Maravelias, C.D., Punzón, A., Sacchi, J., Tidd, A., Tsitsika, E., Marchal, P., Coascoz, N., Mortreux, S., Roos, D. 2011. An investigation of human vs. technology-induced variation in catchability for a selection of European fishing fleets. ICES J. Mar. Sci. 68, 2252-2263.

Marchal, P., Poos, J.J., Quirijns, F. 2007. Linkage between fishers' foraging, market and fish stocks density: examples from some North Sea fisheries. Fish. Res. 83, 33-43.

Maunder, M.N., Punt, A.E. 2004. Standardizing catch and effort data: a review of recent approaches. Fish. Res. 70, 141-159.

Maunder, M.N., Sibert, J.R., Fonteneau, A., Hampton, J., Kleiber, P., Harley, S.J. 2006. Interpreting catch per unit effort data to assess the status of individual stocks and communities. ICES J. Mar. Sci. 63, 1373-1385.

Osorio, F. 2014. Heavy: Package for robust estimation using heavy-tailed distributions. R package version 0.2-35. URL http://cran.r-project.org/package=heavy.

Parente, J. 2004. Predictors of CPUE and standardization of fishing effort for the Portuguese coastal seine fleet. Fish. Res. 69, 381-387.

Pinheiro, J.C., Bates, D.M. 2000. Mixed-Effects Models in S and S-PLUS. Springer, New York.

Pinheiro, J., Bates, D., DebRoy, S., Sarkar, D., R Core Team, 2014. Nlme: Linear and Nonlinear Mixed Effects Models. R package version 3.1-118. URL http://CRAN.Rproject.org/package $=$ nlme .

Pinnegar, J.K., Jennings, S., O’Brien, C.M., Polunin, V.C. 2002. Long-term changes in the trophic level of the Celtic Sea fish community and fish market price distribution. J. Appl. Ecol. 39, 377-390. 
Quirijns, F.J., Poos, J.J., Rijnsdorp, A.D. 2008. Standardizing commercial CPUE data in monitoring stock dynamics: Accounting for targeting behavior in mixed fisheries. Fish. Res. 89, 1-8.

R Core Team. 2014. R: A language and environment for statistical computing. R Foundation for Statistical Computing, Vienna, Austria. URL http://www.R-project.org/.

Rijnsdorp, A.D., Dol, W., Hooyer, M., Pastoors, M.A., 2000. Effects of fishing power and competitive interactions among vessels on the effort allocation on the trip level of the Dutch beam trawl fleet. ICES J. Mar. Sci. 57, 927-937.

Sethi, S.A., Branch, T.A., Watson, R. 2010. Global fishery development patterns are driven by profit but not trophic level. Proc. Natl. Acad. Sci. U.S. 107, 12163-12167.

Singer, J. 1998. Using SAS PROC MIXED to fit multilevel models, hierarchical models, and individual growth models. J. Educ. Behav. Stat. 24, 323-355.

Squires, D. 1987. Long-run profit functions for multiproduct firms. Am. J. Agric. Econ. 69, $558-569$

Sumaila, U.R., Marsden, A.D., Watson, R., Pauly, D. 2007. Global ex-vessel price database: construction and application. J. Bioecon. 9, 39-51.

Swartz, W., Sumaila, R., Watson, R. 2013. Global Ex-vessel Fish Price Database Revisited: A New Approach for Estimating 'Missing' Prices. Environ. Resour. Econ. 56, 467-480.

Tidd, A.N., Hutton, T., Kell, L.T., Blanchard, J.L. 2012. Dynamic prediction of effort reallocation in mixed fisheries. Fish. Res. 125-126, 243-253.

Tidd, A.N. 2013. Effective fishing effort indicators and their application to spatial management of mixed demersal fisheries. Fish. Manag. Ecol. 20, 377-389.

van Oostenbrugge, J.A.E., Poos, J.J., van Densen, W.L.T., Machiels, M.A.M. 2002. In search of a better unit of effort in the coastal liftnet fishery with lights for small pelagics in Indonesia. Fish. Res. 59, 43-56. 
van Putten, I.E., Kulmala, S., Thébaud, O., Dowling, N., Hamon, K.G., Hutton, T., Pascoe, S. 2012. Theories and behavioural drivers underlying fleet dynamics models. Fish Fish. 13, $216-235$

\section{Figures}

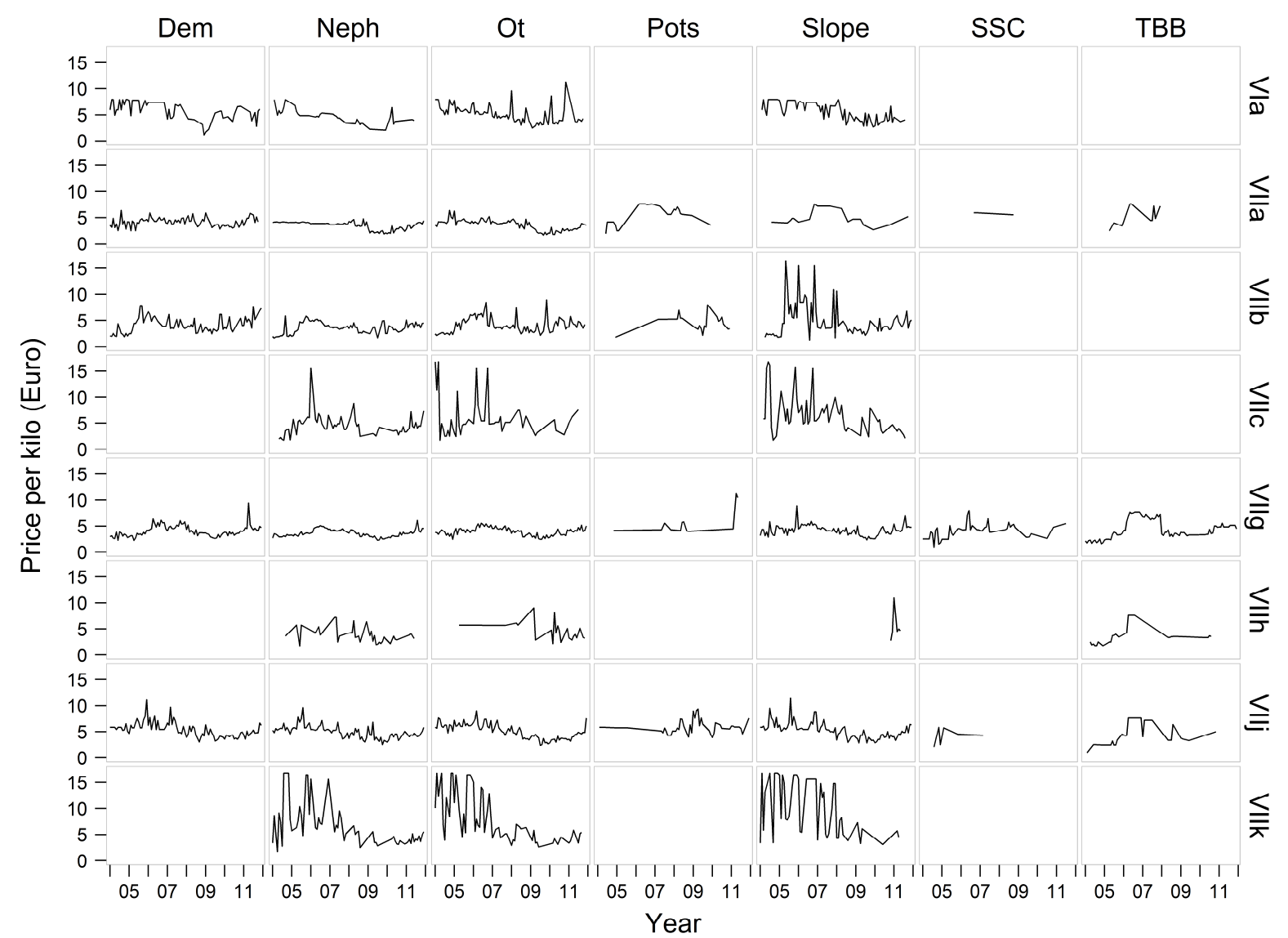

Figure 1. Nephrops monthly average first sale price per kilo for the period 2004-2011 by métier group and ICES division. Categories with minimal landings across the time series have been excluded. 


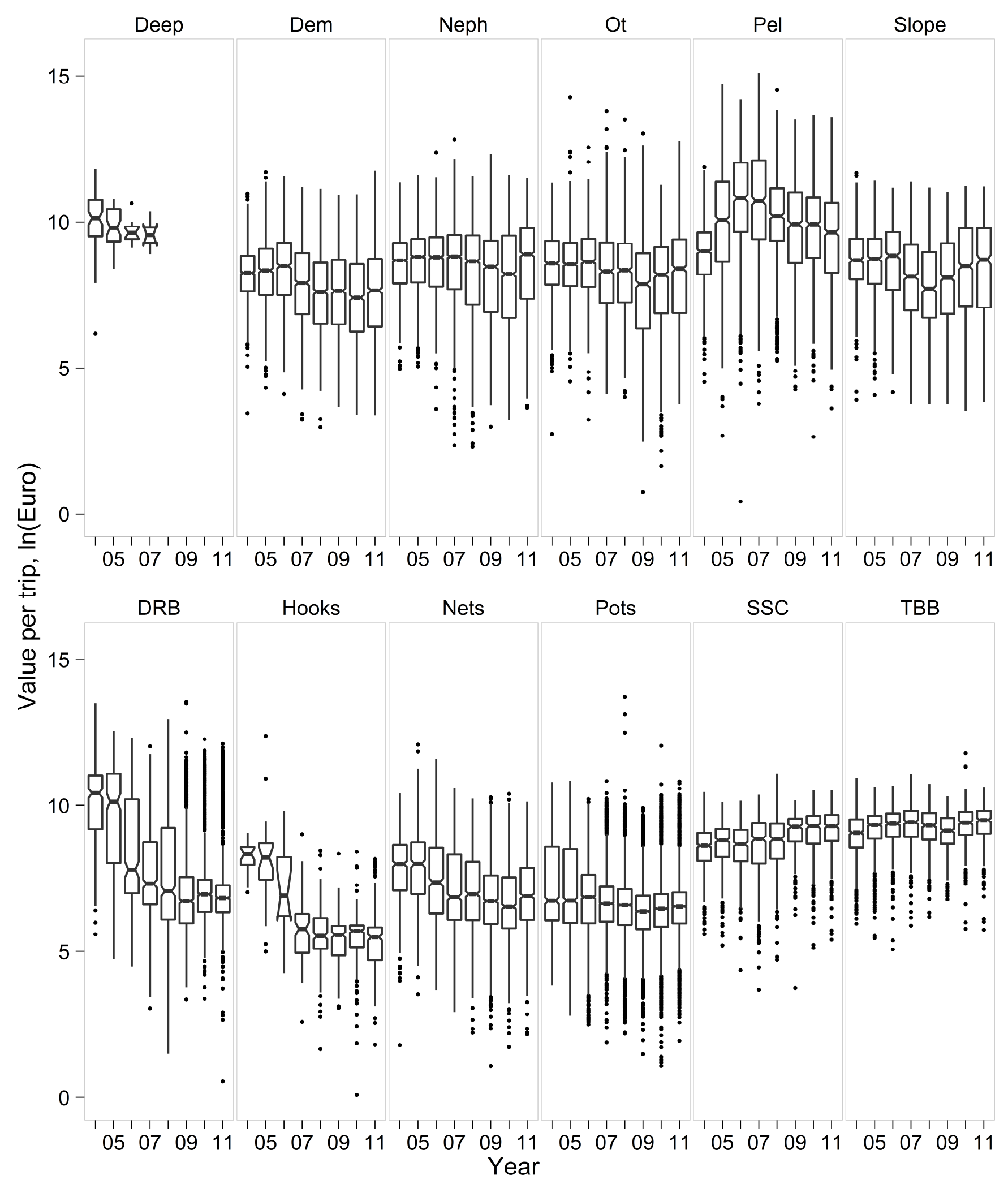

Figure 2. Boxplots for each of the 12 métier groups of natural log transformed Euro value per trip. Notches within boxes represent confidence intervals around the mean. 

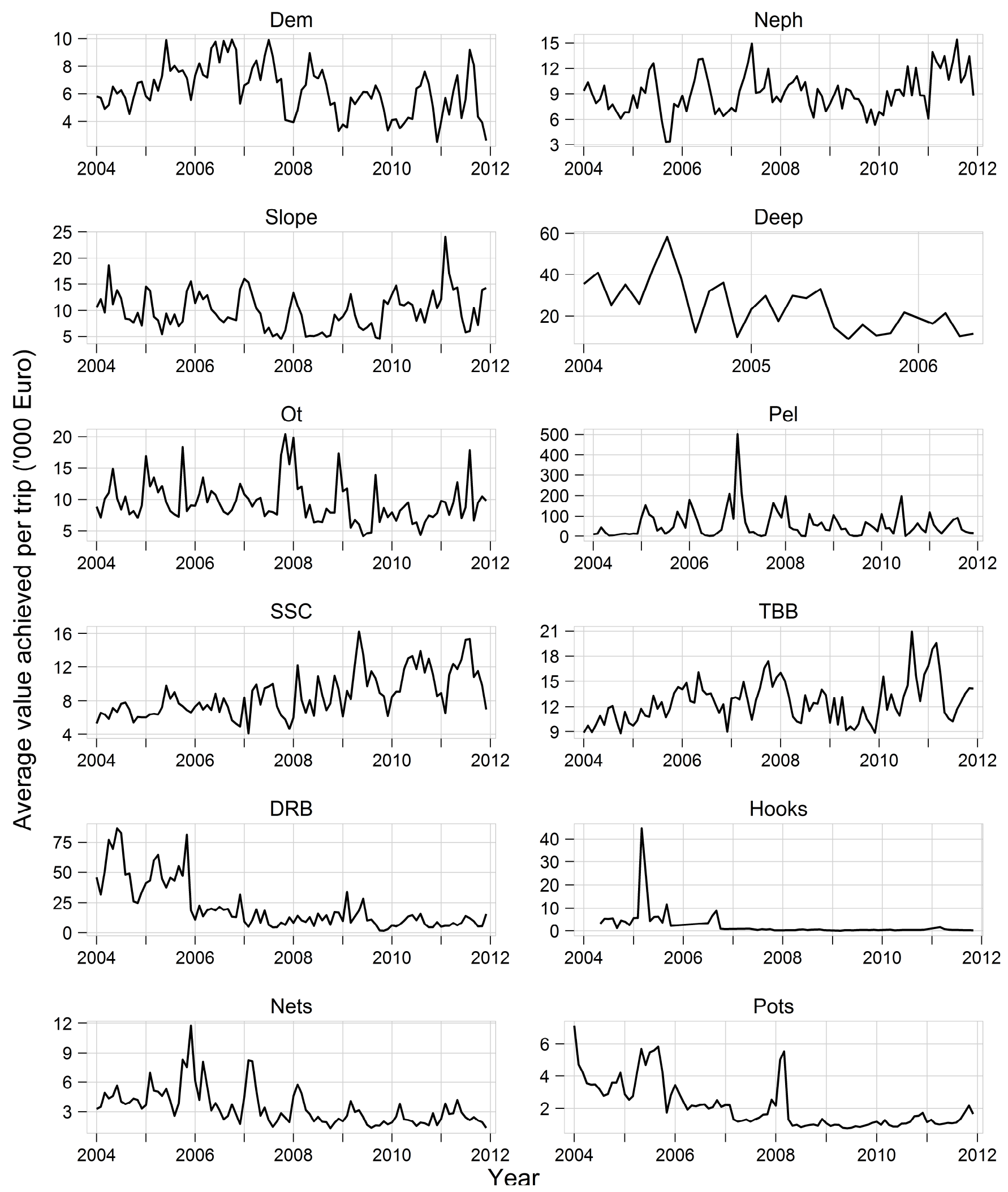

Figure 3. Monthly average fishing trip value ('000 €) for of the period 2004-2011 by métier group. 


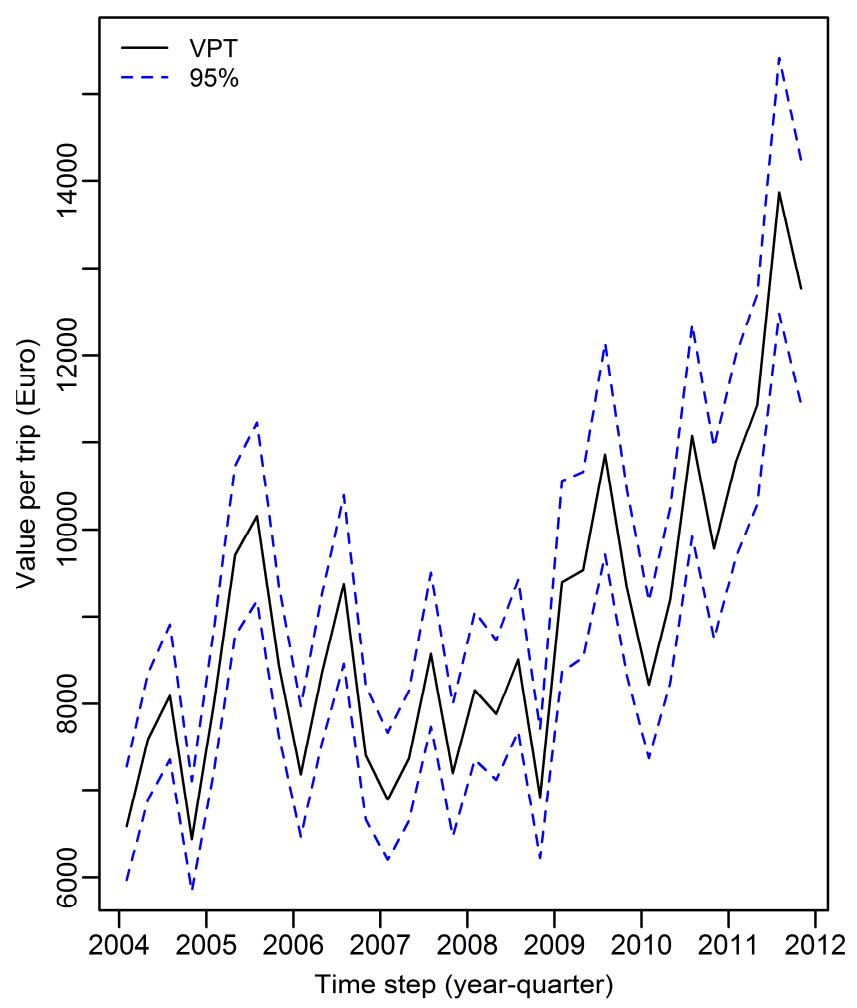

Figure 4. Changes in value per trip (VPT) over the modeled period (2004-2011) as estimated by the final model lme.fd for an average powered Scottish seine vessel $(368 \mathrm{~kW})$ actively fishing four days during a trip.

\section{Tables}

Table 1. Description of data range included within analysis.

\begin{tabular}{|c|c|c|c|c|c|c|c|c|c|}
\hline \multirow[b]{2}{*}{ Métier group } & \multicolumn{2}{|c|}{ No. Vessels } & \multicolumn{2}{|c|}{ No. trips per vessel } & \multirow{2}{*}{$\begin{array}{c}\text { Average engine } \\
\text { power (kW) }\end{array}$} & \multirow{2}{*}{$\begin{array}{l}\text { Average vessel } \\
\text { length }(\mathrm{m})\end{array}$} & \multirow{2}{*}{$\begin{array}{c}\text { Average } \\
\text { days at sea }\end{array}$} & \multirow{2}{*}{$\begin{array}{c}\text { Average } \\
\text { days fishing }\end{array}$} & \multirow{2}{*}{$\begin{array}{c}\text { Average } \\
\text { hours fishing }\end{array}$} \\
\hline & Average & Range & Average & Range & & & & & \\
\hline Deep & 3 & $2-6$ & 9 & $1-32$ & 1052 & 33 & 9 & 7 & 104 \\
\hline Dem & 146 & $120-172$ & 10 & $1-99$ & 282 & 18 & 3 & 2 & 41 \\
\hline DRB & 28 & $16-40$ & 28 & $1-146$ & 165 & 16 & 2 & 1 & 22 \\
\hline Hooks & 19 & $2-37$ & 8 & $1-99$ & 98 & 12 & 1 & 1 & 8 \\
\hline Neph & 148 & $120-171$ & 18 & $1-122$ & 284 & 19 & 4 & 3 & 51 \\
\hline Nets & 61 & $40-83$ & 17 & $1-132$ & 151 & 14 & 2 & 2 & 24 \\
\hline Ot & 168 & $152-192$ & 8 & $1-88$ & 328 & 19 & 4 & 3 & 54 \\
\hline Pel & 71 & $59-85$ & 14 & $1-74$ & 944 & 33 & 3 & 1 & 6 \\
\hline Pots & 102 & $32-138$ & 49 & $1-249$ & 102 & 12 & 1 & 1 & 12 \\
\hline Slope & 122 & $113-143$ & 7 & $1-59$ & 355 & 20 & 4 & 4 & 66 \\
\hline SSC & 12 & 7-19 & 35 & $1-79$ & 343 & 22 & 4 & 3 & 42 \\
\hline TBB & 18 & $11-25$ & 30 & $1-58$ & 540 & 28 & 6 & 5 & 93 \\
\hline
\end{tabular}


Table 2. Effort measure coefficients for the four most relevant models. Notation: Res. Dist. is the type of residual distribution applied within the model; Days are fishing days (ln); kWfD are kilowatt fishing days (ln).

\begin{tabular}{|c|c|c|c|c|c|}
\hline ID & Model & Res. Dist. & Days & Engine & kWfD \\
\hline Ime.kw & $\begin{aligned} \beta_{1, V_{i}}+\alpha_{1, Y_{i}}+ & \alpha_{2, Q_{i}}+\alpha_{3, M_{i}}+\alpha_{4, Y_{i}: M_{i}}+\alpha_{5, Y_{i}: Q_{i}} \\
& +\alpha_{6, M_{i}: Q_{i}}+\beta_{2, M_{i}} \ln \left(k W f D_{i}\right)+\varepsilon_{i}\end{aligned}$ & $N\left(0, \sigma_{M_{i}}^{2}\right)$ & - & - & 1.047 \\
\hline Ime.fd & $\begin{aligned} \beta_{1, V_{i}}+\alpha_{1, Y_{i}}+ & \alpha_{2, Q_{i}}+\alpha_{3, M_{i}}+\alpha_{4, Y_{i}: M_{i}}+\alpha_{5, Y_{i}: Q_{i}} \\
& +\alpha_{6, M_{i}: Q_{i}}+\beta_{2, M_{i}} \ln \left(P_{i}\right) \ln \left(f D_{i}\right)+\varepsilon_{i}\end{aligned}$ & $N\left(0, \sigma_{M_{i}}^{2}\right)$ & 1.038 & 0.713 & - \\
\hline heavy.kw & $\begin{aligned} \beta_{1, V_{i}}+\alpha_{1, Y_{i}}+ & \alpha_{2, Q_{i}}+\alpha_{3, M_{i}}+\alpha_{4, Y_{i}: M_{i}}+\alpha_{5, Y_{i}: Q_{i}} \\
& +\alpha_{6, M_{i}: Q_{i}}+\beta_{2, M_{i}} \ln \left(k W f D_{i}\right)+\varepsilon_{i}\end{aligned}$ & $\begin{array}{l}(1-p) N\left(0, \sigma^{2}\right) \\
+p t_{v}(0)\end{array}$ & - & - & 1.151 \\
\hline heavy.fd & $\begin{aligned} \beta_{1, V_{i}}+\alpha_{1, Y_{i}}+ & \alpha_{2, Q_{i}}+\alpha_{3, M_{i}}+\alpha_{4, Y_{i}: M_{i}}+\alpha_{5, Y_{i}: Q_{i}} \\
& +\alpha_{6, M_{i}: Q_{i}}+\beta_{2, M_{i}} \ln \left(P_{i}\right) \ln \left(f D_{i}\right)+\varepsilon_{i}\end{aligned}$ & $\begin{array}{l}(1-p) N\left(0, \sigma^{2}\right) \\
+p t_{v}(0)\end{array}$ & 1.171 & 0.732 & - \\
\hline
\end{tabular}

Table 3. Overall significance of the interactions between final model variables for value per trip (lme.fd) in which terms are sequentially dropped. Details numerator (num) and denominator (den) degrees of freedoms, F-value and p-value.

\begin{tabular}{lrrrr} 
& numDF & denDF & F-value & p-value \\
\cline { 2 - 5 } (Intercept) & 1 & 126043 & 138281.54 & $<.0001$ \\
Métier & 10 & 126043 & 641.85 & $<.0001$ \\
Year & 7 & 126043 & 267.43 & $<.0001$ \\
Quarter & 3 & 126043 & 351.07 & $<.0001$ \\
In(Effort) & 1 & 126043 & 65334.97 & $<.0001$ \\
In(Engine) & 1 & 705 & 1713.28 & $<.0001$ \\
Métier:Year & 70 & 126043 & 31.20 & $<.0001$ \\
Métier:Quarter & 30 & 126043 & 65.17 & $<.0001$ \\
Year:Quarter & 21 & 126043 & 31.86 & $<.0001$ \\
Métier:In(Effort) & 10 & 126043 & 108.30 & $<.0001$ \\
Métier:In(Engine) & 10 & 126043 & 41.47 & $<.0001$ \\
In(Effort):In(Engine) & 1 & 126043 & 9.50 & 0.0021 \\
Métier:In(Effort):In(Engine) & 10 & 126043 & 34.36 & $<.0001$
\end{tabular}




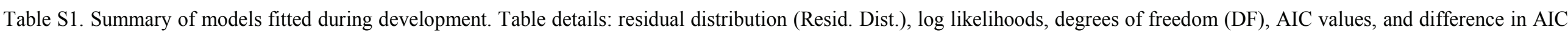

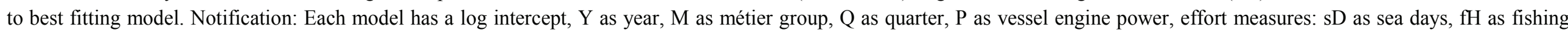
hours, $\mathrm{fD}$ as fishing days, and capacity effort measures: $\mathrm{kWsD}$ as kilowatt sea days, $\mathrm{kWfD}$ as kilowatt fishing days, $\mathrm{kWfH}$ as kilowatt fishing hours.

\begin{tabular}{|c|c|c|c|c|c|c|}
\hline ID & Formula & Res. Dist. & LogLike & df & $\mathrm{AIC}$ & $\triangle \mathrm{AIC}$ \\
\hline $\operatorname{lm}$.Base & $\alpha_{1, Y_{i}}+\alpha_{2, Q_{i}}+\alpha_{3, M_{i}}+\alpha_{4, Y_{i}: M_{i}}+\alpha_{5, Y_{i}: Q_{i}}+\alpha_{6, M_{i}: Q_{i}}+\varepsilon_{i}$ & $N\left(0, \sigma^{2}\right)$ & -210104 & 143 & 420494.9 & 188245.8 \\
\hline $\operatorname{lm} .2 .1$ & $\alpha_{1, Y_{i}}+\alpha_{2, Q_{i}}+\alpha_{3, M_{i}}+\alpha_{4, Y_{i}: M_{i}}+\alpha_{5, Y_{i}: Q_{i}}+\alpha_{6, M_{i}: Q_{i}}+\ln \left(f D_{i}\right)+\varepsilon_{i}$ & $N\left(0, \sigma^{2}\right)$ & -174544 & 143 & 349373.1 & 117124.0 \\
\hline $\operatorname{lm} .1$ & $\alpha_{1, Y_{i}}+\alpha_{2, Q_{i}}+\alpha_{3, M_{i}}+\alpha_{4, Y_{i}: M_{i}}+\alpha_{5, Y_{i}: Q_{i}}+\alpha_{6, M_{i}: Q_{i}}+\beta_{1} \ln \left(f H_{i}\right)+\varepsilon_{i}$ & $N\left(0, \sigma^{2}\right)$ & -171656 & 144 & 343600.0 & 111350.9 \\
\hline $\operatorname{lm} .1 .1$ & $\alpha_{1, Y_{i}}+\alpha_{2, Q_{i}}+\alpha_{3, M_{i}}+\alpha_{4, Y_{i}: M_{i}}+\alpha_{5, Y_{i}: Q_{i}}+\alpha_{6, M_{i}: Q_{i}}+\ln \left(f H_{i}\right)+\varepsilon_{i}$ & $N\left(0, \sigma^{2}\right)$ & -171656 & 143 & 343598.1 & 111349.0 \\
\hline $\operatorname{lm} .0 .1$ & $\alpha_{1, Y_{i}}+\alpha_{2, Q_{i}}+\alpha_{3, M_{i}}+\alpha_{4, Y_{i}: M_{i}}+\alpha_{5, Y_{i}: Q_{i}}+\alpha_{6, M_{i}: Q_{i}}+\ln \left(s D_{i}\right)+\varepsilon_{i}$ & $N\left(0, \sigma^{2}\right)$ & -170091 & 143 & 340468.0 & 108218.9 \\
\hline $\operatorname{lm} .2$ & $\alpha_{1, Y_{i}}+\alpha_{2, Q_{i}}+\alpha_{3, M_{i}}+\alpha_{4, Y_{i}: M_{i}}+\alpha_{5, Y_{i}: Q_{i}}+\alpha_{6, M_{i}: Q_{i}}+\beta_{1} \ln \left(f D_{i}\right)+\varepsilon_{i}$ & $N\left(0, \sigma^{2}\right)$ & -166938 & 144 & 334164.4 & 101915.3 \\
\hline $\operatorname{lm} .0$ & $\alpha_{1, Y_{i}}+\alpha_{2, Q_{i}}+\alpha_{3, M_{i}}+\alpha_{4, Y_{i}: M_{i}}+\alpha_{5, Y_{i}: Q_{i}}+\alpha_{6, M_{i}: Q_{i}}+\beta_{1} \ln \left(s D_{i}\right)+\varepsilon_{i}$ & $N\left(0, \sigma^{2}\right)$ & -163790 & 144 & 327868.5 & 95619.4 \\
\hline $\operatorname{lm} .4 .1$ & $\alpha_{1, Y_{i}}+\alpha_{2, Q_{i}}+\alpha_{3, M_{i}}+\alpha_{4, Y_{i}: M_{i}}+\alpha_{5, Y_{i}: Q_{i}}+\alpha_{6, M_{i}: Q_{i}}+\ln \left(k W f H_{i}\right)+\varepsilon_{i}$ & $N\left(0, \sigma^{2}\right)$ & -163485 & 143 & 327256.9 & 95007.8 \\
\hline $\operatorname{lm} .4$ & $\alpha_{1, Y_{i}}+\alpha_{2, Q_{i}}+\alpha_{3, M_{i}}+\alpha_{4, Y_{i}: M_{i}}+\alpha_{5, Y_{i}: Q_{i}}+\alpha_{6, M_{i}: Q_{i}}+\beta_{1} \ln \left(k W f H_{i}\right)+\varepsilon_{i}$ & $N\left(0, \sigma^{2}\right)$ & -156384 & 144 & 313055.8 & 80806.7 \\
\hline $\operatorname{lm} .3 .1$ & $\alpha_{1, Y_{i}}+\alpha_{2, Q_{i}}+\alpha_{3, M_{i}}+\alpha_{4, Y_{i}: M_{i}}+\alpha_{5, Y_{i}: Q_{i}}+\alpha_{6, M_{i}: Q_{i}}+\ln \left(k W s D_{i}\right)+\varepsilon_{i}$ & $N\left(0, \sigma^{2}\right)$ & -156363 & 143 & 313011.1 & 80762.0 \\
\hline $\operatorname{lm} .6 .1$ & $\alpha_{1, Y_{i}}+\alpha_{2, Q_{i}}+\alpha_{3, M_{i}}+\alpha_{4, Y_{i}: M_{i}}+\alpha_{5, Y_{i}: Q_{i}}+\alpha_{6, M_{i}: Q_{i}}+\ln \left(P_{i}\right)+\ln \left(s D_{i}\right)+\varepsilon_{i}$ & $N\left(0, \sigma^{2}\right)$ & -156363 & 143 & 313011.1 & 80762.0 \\
\hline $\operatorname{lm} .6 .3$ & $\alpha_{1, Y_{i}}+\alpha_{2, Q_{i}}+\alpha_{3, M_{i}}+\alpha_{4, Y_{i}: M_{i}}+\alpha_{5, Y_{i}: Q_{i}}+\alpha_{6, M_{i}: Q_{i}}+\ln \left(P_{i}\right)+\beta_{1} \ln \left(s D_{i}\right)+\varepsilon_{i}$ & $N\left(0, \sigma^{2}\right)$ & -156242 & 144 & 312772.6 & 80523.5 \\
\hline $\operatorname{lm} .5 .1$ & $\alpha_{1, Y_{i}}+\alpha_{2, Q_{i}}+\alpha_{3, M_{i}}+\alpha_{4, Y_{i}: M_{i}}+\alpha_{5, Y_{i}: Q_{i}}+\alpha_{6, M_{i}: Q_{i}}+\ln \left(k W f D_{i}\right)+\varepsilon_{i}$ & $N\left(0, \sigma^{2}\right)$ & -155862 & 143 & 312010.2 & 79761.1 \\
\hline $\operatorname{lm} .7 .1$ & $\alpha_{1, Y_{i}}+\alpha_{2, Q_{i}}+\alpha_{3, M_{i}}+\alpha_{4, Y_{i}: M_{i}}+\alpha_{5, Y_{i}: Q_{i}}+\alpha_{6, M_{i}: Q_{i}}+\ln \left(P_{i}\right)+\ln \left(f D_{i}\right)+\varepsilon_{i}$ & $N\left(0, \sigma^{2}\right)$ & -155862 & 143 & 312010.2 & 79761.1 \\
\hline $\operatorname{lm} .9 .1$ & $\alpha_{1, Y_{i}}+\alpha_{2, Q_{i}}+\alpha_{3, M_{i}}+\alpha_{4, Y_{i}: M_{i}}+\alpha_{5, Y_{i}: Q_{i}}+\alpha_{6, M_{i}: Q_{i}}+\ln \left(P_{i}\right) \ln \left(f D_{i}\right)+\varepsilon_{i}$ & $N\left(0, \sigma^{2}\right)$ & -155862 & 143 & 312010.2 & 79761.1 \\
\hline $\operatorname{lm} .7 .3$ & $\alpha_{1, Y_{i}}+\alpha_{2, Q_{i}}+\alpha_{3, M_{i}}+\alpha_{4, Y_{i}: M_{i}}+\alpha_{5, Y_{i}: Q_{i}}+\alpha_{6, M_{i}: Q_{i}}+\ln \left(P_{i}\right)+\beta_{1} \ln \left(f D_{i}\right)+\varepsilon_{i}$ & $N\left(0, \sigma^{2}\right)$ & -155792 & 144 & 311872.7 & 79623.6 \\
\hline $\operatorname{lm} .9 .3$ & $\alpha_{1, Y_{i}}+\alpha_{2, Q_{i}}+\alpha_{3, M_{i}}+\alpha_{4, Y_{i}: M_{i}}+\alpha_{5, Y_{i}: Q_{i}}+\alpha_{6, M_{i}: Q_{i}}+\beta_{1} \ln \left(f D_{i}\right)+\ln \left(P_{i}\right)+\beta_{2} \ln \left(f D_{i} P_{i}\right)+\varepsilon_{i}$ & $N\left(0, \sigma^{2}\right)$ & -155792 & 144 & 311872.7 & 79623.6 \\
\hline $\operatorname{lm} .5$ & $\alpha_{1, Y_{i}}+\alpha_{2, Q_{i}}+\alpha_{3, M_{i}}+\alpha_{4, Y_{i}: M_{i}}+\alpha_{5, Y_{i}: Q_{i}}+\alpha_{6, M_{i}: Q_{i}}+\beta_{1} \ln \left(k W f D_{i}\right)+\varepsilon_{i}$ & $N\left(0, \sigma^{2}\right)$ & -155690 & 144 & 311667.2 & 79418.1 \\
\hline $\operatorname{lm} .3$ & $\alpha_{1, Y_{i}}+\alpha_{2, Q_{i}}+\alpha_{3, M_{i}}+\alpha_{4, Y_{i}: M_{i}}+\alpha_{5, Y_{i}: Q_{i}}+\alpha_{6, M_{i}: Q_{i}}+\beta_{1} \ln \left(k W s D_{i}\right)+\varepsilon_{i}$ & $N\left(0, \sigma^{2}\right)$ & -155287 & 144 & 310861.3 & 78612.2 \\
\hline $\operatorname{lm} .7 .2$ & $\alpha_{1, Y_{i}}+\alpha_{2, Q_{i}}+\alpha_{3, M_{i}}+\alpha_{4, Y_{i}: M_{i}}+\alpha_{5, Y_{i}: Q_{i}}+\alpha_{6, M_{i}: Q_{i}}+\beta_{1} \ln \left(P_{i}\right)+\ln \left(f D_{i}\right)+\varepsilon_{i}$ & $N\left(0, \sigma^{2}\right)$ & -154941 & 144 & 310169.4 & 77920.3 \\
\hline $\operatorname{lm} .9 .2$ & $\alpha_{1, Y_{i}}+\alpha_{2, Q_{i}}+\alpha_{3, M_{i}}+\alpha_{4, Y_{i}: M_{i}}+\alpha_{5, Y_{i}: Q_{i}}+\alpha_{6, M_{i}: Q_{i}}+\ln \left(f D_{i}\right)+\beta_{1} \ln \left(P_{i}\right)+\beta_{2} \ln \left(f D_{i} P_{i}\right)+\varepsilon_{i}$ & $N\left(0, \sigma^{2}\right)$ & -154941 & 144 & 310169.4 & 77920.3 \\
\hline
\end{tabular}


$-131561$

239304549.5

$N\left(0, \sigma^{2}\right)$

$-131555$

$145 \quad 263412.3$

72300.4

$N\left(0, \sigma^{2}\right)$

$147 \quad 263404.1$

31163.2

lme.5.1

$\beta_{1, M_{i, V[i]}}+\alpha_{1, Y_{i} Q_{i}}+\left(\alpha_{2}+\beta_{2, M_{i, V[i]}}\right) \ln \left(k W f D_{i}\right)+\varepsilon_{i}$

$\operatorname{lm} .10$

$\alpha_{1, Y_{i}}+\alpha_{2, Q_{i}}+\alpha_{3, M_{i}}+\alpha_{4, M_{i}}+\alpha_{5, Y_{i}: M_{i}}+\alpha_{6, Y_{i}: Q_{i}}+\alpha_{7, M_{i}: Q_{i}}+\beta_{1} \ln \left(P_{i}\right)+\beta_{2}\left(f D_{i}\right)+\varepsilon_{i}$

lme.5.2

$\beta_{1, V_{i}}+\alpha_{1, Y_{i}}+\alpha_{2, Q_{i}}+\alpha_{3, M_{i}}+\alpha_{4, Y_{i}: M_{i}}+\alpha_{5, Y_{i}: Q_{i}}+\alpha_{6, M_{i}: Q_{i}}+\left(\alpha_{7}+\beta_{2, V_{i}}\right) \ln \left(k W f D_{i}\right)+\varepsilon_{i}$

lme.3.3

$\beta_{1, V_{i}}+\alpha_{1, Y_{i}}+\alpha_{2, Q_{i}}+\alpha_{3, M_{i}}+\alpha_{4, Y_{i}: M_{i}}+\alpha_{5, Y_{i}: Q_{i}}+\alpha_{6, M_{i}: Q_{i}}+\beta_{2} \ln \left(k W s D_{i}\right)+\varepsilon_{i}$

lme.8.1

$\beta_{1, V_{i}}+\alpha_{1, Y_{i}}+\alpha_{2, Q_{i}}+\alpha_{3, M_{i}}+\alpha_{4, Y_{i}: M_{i}}+\alpha_{5, Y_{i}: Q_{i}}+\alpha_{6, M_{i}: Q_{i}}+\beta_{2} \ln \left(P_{i}\right) \ln \left(s D_{i}\right)+\varepsilon_{i}$

lme.3.4

$\beta_{1, V_{i}}+\alpha_{1, Y_{i}}+\alpha_{2, Q_{i}}+\alpha_{3, M_{i}}+\alpha_{4, Y_{i}: M_{i}}+\alpha_{5, Y_{i}: Q_{i}}+\alpha_{6, M_{i}: Q_{i}}+\beta_{2, M_{i}} \ln \left(k W s D_{i}\right)+\varepsilon_{i}$

lme. 13.1

$\beta_{1, V_{i}}+\alpha_{1, Y_{i}}+\alpha_{2, Q_{i}}+\alpha_{3, M_{i}}+\alpha_{4, Y_{i}: M_{i}}+\alpha_{5, Y_{i}: Q_{i}}+\alpha_{6, M_{i}: Q_{i}}+\beta_{2, M_{i}} \ln \left(P_{i}\right) \ln \left(s D_{i}\right)+\varepsilon_{i}$

$\operatorname{lme} .5 .3$

$\beta_{1, V_{i}}+\alpha_{1, Y_{i}}+\alpha_{2, Q_{i}}+\alpha_{3, M_{i}}+\alpha_{4, Y_{i}: M_{i}}+\alpha_{5, Y_{i}: Q_{i}}+\alpha_{6, M_{i}: Q_{i}}+\beta_{2} \ln \left(k W f D_{i}\right)+\varepsilon_{i}$

$N\left(0, \sigma^{2}\right)$

$N\left(0, \sigma^{2}\right)$

$N\left(0, \sigma^{2}\right)$

$N\left(0, \sigma^{2}\right)$

$N\left(0, \sigma_{M_{i}}^{2}\right)$

$N\left(0, \sigma_{M_{i}}^{2}\right)$

$N\left(0, \sigma_{M_{i}}^{2}\right)$

$N\left(0, \sigma_{M_{i}}^{2}\right)$

$N\left(0, \sigma_{M_{i}}^{2}\right)$

$N\left(0, \sigma_{M_{i}}^{2}\right)$
$-129665$

$-130289$

$851 \quad 261031.5$

$40 \quad 260658.8$

$-129285$

$147 \quad 258864.9$

$-128943$

$145 \quad 258176.5$

$-128816$

$-128217$

$147 \quad 257925.4$

$40 \quad 256513.3$

$-126874$

$851 \quad 255450.3$

$-126938$

$147 \quad 254170.6$

$-125985$

$155 \quad 252279.9$

$-125738$

$157 \quad 251790.2$

$-125252$

$165 \quad 250834.9$

$-124599$

$187 \quad 249572.8$

$-122338$

$155 \quad 244986.0$

$-122320$
31155.0

28782.4

28409.7

26615.8

25927.3

25676.3

24264.2

23201.2

21921.5

20030.8

19541.1

18585.8

17323.7

12736.9

12704.6 
Table S1. Continued

lme.kwfd $\quad \beta_{1, V_{i}}+\alpha_{1, Y_{i}}+\alpha_{2, Q_{i}}+\alpha_{3, M_{i}}+\alpha_{4, Y_{i}: M_{i}}+\alpha_{5, Y_{i}: Q_{i}}+\alpha_{6, M_{i}: Q_{i}}+\beta_{2, M_{i}} \ln \left(k W f D_{i}\right)+\varepsilon_{i}$

lme.fd $\quad \beta_{1, V_{i}}+\alpha_{1, Y_{i}}+\alpha_{2, Q_{i}}+\alpha_{3, M_{i}}+\alpha_{4, Y_{i}: M_{i}}+\alpha_{5, Y_{i}: Q_{i}}+\alpha_{6, M_{i}: Q_{i}}+\beta_{2, M_{i}} \ln \left(P_{i}\right) \ln \left(f D_{i}\right)+\varepsilon_{i}$

heavy.kwfd $\beta_{1, V_{i}}+\alpha_{1, Y_{i}}+\alpha_{2, Q_{i}}+\alpha_{3, M_{i}}+\alpha_{4, Y_{i}: M_{i}}+\alpha_{5, Y_{i}: Q_{i}}+\alpha_{6, M_{i}: Q_{i}}+\beta_{2, M_{i}} \ln \left(k W f D_{i}\right)+\varepsilon_{i}$

heavy.fd

$\beta_{1, V_{i}}+\alpha_{1, Y_{i}}+\alpha_{2, Q_{i}}+\alpha_{3, M_{i}}+\alpha_{4, Y_{i}: M_{i}}+\alpha_{5, Y_{i}: Q_{i}}+\alpha_{6, M_{i}: Q_{i}}+\beta_{2, M_{i}} \ln \left(P_{i}\right) \ln \left(f D_{i}\right)+\varepsilon_{i}$

$\begin{array}{crrrr}N\left(0, \sigma_{M_{i}}^{2}\right) & -122017 & 165 & 244363.2 & 12114.1 \\ N\left(0, \sigma_{M_{i}}^{2}\right) & -121413 & 187 & 243200.3 & 10951.2 \\ (1-p) N\left(0, \sigma^{2}\right)+p t_{v}(0) & -116119 & 157 & 232554.5 & 305.4 \\ (1-p) N\left(0, \sigma^{2}\right)+p t_{v}(0) & -115945 & 180 & 232249.1 & 0.0\end{array}$


Table S2. Fixed effects coefficients from the final value per trip model (lme.fd). The intercept represents a combination of 2004, quarter 1, and the demersal métier group.

\begin{tabular}{|c|c|c|c|c|c|c|c|c|c|c|c|}
\hline & Value $s$ & Std.Error & DF & t-value & $p$-value & & Value & Std.Error & DF & t-value & $\mathrm{p}$-value \\
\hline Intercept & 3.152 & 0.157 & 126043 & 20.034 & 0.000 & Interactions cont. & & & & & \\
\hline Métier groups & & & & & & neph:2007 & -0.040 & 0.026 & 126043 & -1.497 & 0.134 \\
\hline DRB & -1.509 & 0.258 & 126043 & -5.859 & 0.000 & Nets:2007 & 0.227 & 0.047 & 126043 & 4.867 & 0.000 \\
\hline Hooks & 0.124 & 0.479 & 126043 & 0.260 & 0.795 & Ot:2007 & 0.011 & 0.030 & 126043 & 0.376 & 0.707 \\
\hline neph & -0.334 & 0.114 & 126043 & -2.925 & 0.003 & Pel:2007 & 1.346 & 0.060 & 126043 & 22.533 & 0.000 \\
\hline Nets & -0.666 & 0.184 & 126043 & -3.613 & 0.000 & Pots:2007 & -0.028 & 0.032 & 126043 & -0.874 & 0.382 \\
\hline Ot & -1.085 & 0.122 & 126043 & -8.903 & 0.000 & slope:2007 & -0.019 & 0.036 & 126043 & -0.521 & 0.603 \\
\hline Pel & -2.198 & 0.183 & 126043 & -12.025 & 0.000 & SSC:2007 & 0.030 & 0.041 & 126043 & 0.716 & 0.474 \\
\hline Pots & -0.762 & 0.175 & 126043 & -4.360 & 0.000 & TBB:2007 & 0.409 & 0.034 & 126043 & 12.006 & 0.000 \\
\hline slope & -0.451 & 0.139 & 126043 & -3.243 & 0.001 & DRB:2008 & 0.089 & 0.080 & 126043 & 1.108 & 0.268 \\
\hline SSC & -4.200 & 0.649 & 126043 & -6.469 & 0.000 & Hooks:2008 & -0.230 & 0.306 & 126043 & -0.750 & 0.453 \\
\hline TBB & -2.611 & 0.445 & 126043 & -5.864 & 0.000 & neph:2008 & 0.072 & 0.027 & 126043 & 2.637 & 0.008 \\
\hline Years & & & & & & Nets:2008 & 0.279 & 0.046 & 126043 & 6.060 & 0.000 \\
\hline 2005 & -0.119 & 0.025 & 126043 & -4.697 & 0.000 & Ot:2008 & 0.086 & 0.032 & 126043 & 2.718 & 0.007 \\
\hline 2006 & -0.098 & 0.027 & 126043 & -3.658 & 0.000 & Pel:2008 & 1.094 & 0.060 & 126043 & 18.371 & 0.000 \\
\hline 2007 & 0.016 & 0.026 & 126043 & 0.607 & 0.544 & Pots:2008 & 0.076 & 0.033 & 126043 & 2.347 & 0.019 \\
\hline 2008 & 0.000 & 0.026 & 126043 & 0.000 & 1.000 & slope:2008 & 0.115 & 0.037 & 126043 & 3.123 & 0.002 \\
\hline 2009 & -0.108 & 0.025 & 126043 & -4.270 & 0.000 & SSC:2008 & 0.214 & 0.044 & 126043 & 4.902 & 0.000 \\
\hline 2010 & -0.270 & 0.025 & 126043 & -10.580 & 0.000 & TBB:2008 & 0.584 & 0.037 & 126043 & 15.666 & 0.000 \\
\hline 2011 & -0.034 & 0.026 & 126043 & -1.316 & 0.188 & DRB:2009 & 0.032 & 0.079 & 126043 & 0.405 & 0.686 \\
\hline Quarters & & & & & & Hooks:2009 & -0.087 & 0.306 & 126043 & -0.285 & 0.776 \\
\hline Q2 & 0.094 & 0.021 & 126043 & 4.460 & 0.000 & neph:2009 & -0.053 & 0.027 & 126043 & -1.984 & 0.047 \\
\hline Q3 & 0.096 & 0.021 & 126043 & 4.522 & 0.000 & Nets:2009 & 0.151 & 0.045 & 126043 & 3.336 & 0.001 \\
\hline Q4 & 0.008 & 0.021 & 126043 & 0.383 & 0.701 & Ot:2009 & 0.034 & 0.031 & 126043 & 1.104 & 0.269 \\
\hline In(Effort) & 1.038 & 0.081 & 126043 & 12.856 & 0.000 & Pel:2009 & 0.962 & 0.058 & 126043 & 16.617 & 0.000 \\
\hline In(Engine) & 0.713 & 0.029 & 705 & 24.487 & 0.000 & Pots:2009 & 0.019 & 0.032 & 126043 & 0.593 & 0.553 \\
\hline Interactions & & & & & & slope:2009 & 0.049 & 0.036 & 126043 & 1.366 & 0.172 \\
\hline DRB:2005 & 0.323 & 0.067 & 126043 & 4.852 & 0.000 & SSC:2009 & 0.463 & 0.051 & 126043 & 9.089 & 0.000 \\
\hline Hooks:2005 & -0.031 & 0.238 & 126043 & -0.129 & 0.897 & TBB:2009 & 0.474 & 0.037 & 126043 & 12.955 & 0.000 \\
\hline neph:2005 & 0.055 & 0.026 & 126043 & 2.133 & 0.033 & DRB:2010 & 0.168 & 0.079 & 126043 & 2.125 & 0.034 \\
\hline Nets:2005 & 0.100 & 0.050 & 126043 & 1.975 & 0.048 & Hooks:2010 & -0.017 & 0.307 & 126043 & -0.054 & 0.957 \\
\hline Ot:2005 & 0.146 & 0.029 & 126043 & 4.980 & 0.000 & neph:2010 & 0.024 & 0.027 & 126043 & 0.874 & 0.382 \\
\hline Pel:2005 & 1.044 & 0.056 & 126043 & 18.668 & 0.000 & Nets:2010 & 0.152 & 0.046 & 126043 & 3.311 & 0.001 \\
\hline Pots:2005 & 0.181 & 0.034 & 126043 & 5.386 & 0.000 & Ot:2010 & 0.129 & 0.031 & 126043 & 4.155 & 0.000 \\
\hline slope:2005 & 0.192 & 0.037 & 126043 & 5.171 & 0.000 & Pel:2010 & 1.039 & 0.059 & 126043 & 17.718 & 0.000 \\
\hline SSC:2005 & 0.312 & 0.039 & 126043 & 7.967 & 0.000 & Pots:2010 & 0.151 & 0.032 & 126043 & 4.714 & 0.000 \\
\hline TBB:2005 & 0.270 & 0.032 & 126043 & 8.402 & 0.000 & slope:2010 & 0.124 & 0.036 & 126043 & 3.409 & 0.001 \\
\hline DRB:2006 & 0.308 & 0.080 & 126043 & 3.849 & 0.000 & SSC:2010 & 0.491 & 0.051 & 126043 & 9.681 & 0.000 \\
\hline Hooks:2006 & 0.074 & 0.337 & 126043 & 0.218 & 0.827 & TBB:2010 & 0.656 & 0.037 & 126043 & 17.537 & 0.000 \\
\hline neph:2006 & 0.055 & 0.027 & 126043 & 1.992 & 0.046 & DRB:2011 & 0.030 & 0.078 & 126043 & 0.381 & 0.703 \\
\hline Nets:2006 & 0.070 & 0.050 & 126043 & 1.408 & 0.159 & Hooks:2011 & -0.440 & 0.307 & 126043 & -1.432 & 0.152 \\
\hline Ot:2006 & 0.119 & 0.031 & 126043 & 3.802 & 0.000 & neph:2011 & 0.026 & 0.028 & 126043 & 0.946 & 0.344 \\
\hline Pel:2006 & 1.491 & 0.060 & 126043 & 24.949 & 0.000 & Nets:2011 & 0.128 & 0.047 & 126043 & 2.703 & 0.007 \\
\hline Pots:2006 & -0.032 & 0.033 & 126043 & -0.963 & 0.336 & Ot:2011 & 0.082 & 0.031 & 126043 & 2.627 & 0.009 \\
\hline slope:2006 & 0.121 & 0.038 & 126043 & 3.235 & 0.001 & Pel:2011 & 1.161 & 0.058 & 126043 & 19.881 & 0.000 \\
\hline SSC:2006 & 0.184 & 0.041 & 126043 & 4.517 & 0.000 & Pots:2011 & 0.053 & 0.032 & 126043 & 1.625 & 0.104 \\
\hline TBB:2006 & 0.417 & 0.034 & 126043 & 12.184 & 0.000 & slope:2011 & -0.020 & 0.038 & 126043 & -0.521 & 0.602 \\
\hline DRB:2007 & -0.226 & 0.079 & 126043 & -2.873 & 0.004 & SSC:2011 & 0.527 & 0.049 & 126043 & 10.741 & 0.000 \\
\hline Hooks:2007 & -0.254 & 0.305 & 126043 & -0.832 & 0.405 & TBB:2011 & 0.575 & 0.038 & 126043 & 15.153 & 0.000 \\
\hline DRB:Q2 & 0.028 & 0.031 & 126043 & 0.912 & 0.362 & 2009:Q4 & 0.015 & 0.022 & 126043 & 0.655 & 0.513 \\
\hline Hooks:Q2 & -0.301 & 0.164 & 126043 & -1.840 & 0.066 & 2010:Q4 & 0.197 & 0.022 & 126043 & 8.843 & 0.000 \\
\hline neph:Q2 & 0.047 & 0.018 & 126043 & 2.646 & 0.008 & 2011:Q4 & 0.192 & 0.023 & 126043 & 8.501 & 0.000 \\
\hline Nets:Q2 & -0.105 & 0.027 & 126043 & -3.823 & 0.000 & DRB:In(Effort) & -1.837 & 0.177 & 126043 & -10.383 & 0.000 \\
\hline Ot:Q2 & 0.012 & 0.022 & 126043 & 0.549 & 0.583 & Hooks:In(Effort) & 0.227 & 0.578 & 126043 & 0.393 & 0.695 \\
\hline Pel:Q2 & -0.903 & 0.078 & 126043 & -11.529 & 0.000 & neph:In(Effort) & 0.028 & 0.098 & 126043 & 0.289 & 0.773 \\
\hline Pots:Q2 & 0.086 & 0.018 & 126043 & 4.690 & 0.000 & Nets:In(Effort) & 0.467 & 0.165 & 126043 & 2.822 & 0.005 \\
\hline slope:Q2 & -0.097 & 0.024 & 126043 & -4.121 & 0.000 & Ot:In(Effort) & 0.379 & 0.097 & 126043 & 3.895 & 0.000 \\
\hline SSC:Q2 & 0.047 & 0.031 & 126043 & 1.520 & 0.129 & Pel:In(Effort) & 1.399 & 0.254 & 126043 & 5.503 & 0.000 \\
\hline TBB:Q2 & -0.100 & 0.024 & 126043 & -4.112 & 0.000 & Pots:In(Effort) & 0.233 & 0.125 & 126043 & 1.863 & 0.062 \\
\hline DRB:Q3 & -0.041 & 0.030 & 126043 & -1.354 & 0.176 & slope:In(Effort) & 0.305 & 0.111 & 126043 & 2.741 & 0.006 \\
\hline Hooks:Q3 & -0.304 & 0.161 & 126043 & -1.890 & 0.059 & SSC:In(Effort) & 3.125 & 0.404 & 126043 & 7.737 & 0.000 \\
\hline neph:Q3 & -0.123 & 0.018 & 126043 & -6.906 & 0.000 & TBB:In(Effort) & -0.049 & 0.168 & 126043 & -0.293 & 0.770 \\
\hline Nets:Q3 & -0.340 & 0.028 & 126043 & -12.234 & 0.000 & DRB:In(Engine) & 0.406 & 0.049 & 126043 & 8.235 & 0.000 \\
\hline Ot:Q3 & -0.102 & 0.021 & 126043 & -4.725 & 0.000 & Hooks:In(Engine) & -0.114 & 0.070 & 126043 & -1.637 & 0.102 \\
\hline Pel:Q3 & -0.809 & 0.049 & 126043 & -16.587 & 0.000 & neph:In(Engine) & 0.115 & 0.021 & 126043 & 5.442 & 0.000 \\
\hline Pots:Q3 & 0.102 & 0.018 & 126043 & 5.676 & 0.000 & Nets:In(Engine) & 0.188 & 0.037 & 126043 & 5.067 & 0.000 \\
\hline slope:Q3 & -0.256 & 0.023 & 126043 & -10.968 & 0.000 & Ot:In(Engine) & 0.260 & 0.023 & 126043 & 11.526 & 0.000 \\
\hline SSC:Q3 & 0.110 & 0.031 & 126043 & 3.587 & 0.000 & Pel:In(Engine) & 0.508 & 0.030 & 126043 & 16.700 & 0.000 \\
\hline TBB:Q3 & -0.109 & 0.024 & 126043 & -4.483 & 0.000 & Pots:In(Engine) & 0.156 & 0.036 & 126043 & 4.283 & 0.000 \\
\hline DRB:Q4 & -0.101 & 0.030 & 126043 & -3.386 & 0.001 & slope:In(Engine) & 0.074 & 0.025 & 126043 & 2.914 & 0.004 \\
\hline Hooks:Q4 & -0.238 & 0.168 & 126043 & -1.416 & 0.157 & SSC:In(Engine) & 0.722 & 0.111 & 126043 & 6.484 & 0.000 \\
\hline neph:Q4 & -0.143 & 0.018 & 126043 & -7.921 & 0.000 & TBB:In(Engine) & 0.366 & 0.077 & 126043 & 4.721 & 0.000 \\
\hline Nets:Q4 & -0.432 & 0.031 & 126043 & -13.901 & 0.000 & $\ln ($ Effort):In(Engine) & 0.019 & 0.015 & 126043 & 1.336 & 0.182 \\
\hline Ot:Q4 & -0.074 & 0.022 & 126043 & -3.396 & 0.001 & DRB:In(Effort):In(Engine) & 0.330 & 0.033 & 126043 & 9.884 & 0.000 \\
\hline Pel:Q4 & -0.528 & 0.031 & 126043 & -16.771 & 0.000 & Hooks:In(Effort):In(Engine) & -0.050 & 0.111 & 126043 & -0.447 & 0.655 \\
\hline
\end{tabular}


Table S2. Continued

$\begin{array}{lrrrrr} & \text { Value } & \text { Std.Error } & \text { DF } & \text { t-value } & \text { p-value } \\ \text { Interactions cont. } & & & & & \\ \text { Pots:Q4 } & 0.149 & 0.018 & 126043 & 8.082 & 0.000 \\ \text { slope:Q4 } & -0.167 & 0.023 & 126043 & -7.233 & 0.000 \\ \text { SSC:Q4 } & -0.031 & 0.031 & 126043 & -0.976 & 0.329 \\ \text { TBB:Q4 } & 0.027 & 0.024 & 126043 & 1.137 & 0.256 \\ \text { 2005:Q2 } & 0.054 & 0.022 & 126043 & 2.487 & 0.013 \\ \text { 2006:Q2 } & 0.010 & 0.022 & 126043 & 0.462 & 0.644 \\ \text { 2007:Q2 } & -0.075 & 0.021 & 126043 & -3.546 & 0.000 \\ \text { 2008:Q2 } & -0.175 & 0.021 & 126043 & -8.323 & 0.000 \\ \text { 2009:Q2 } & -0.127 & 0.021 & 126043 & -5.964 & 0.000 \\ \text { 2010:Q2 } & -0.030 & 0.021 & 126043 & -1.436 & 0.151 \\ \text { 2011:Q2 } & -0.082 & 0.021 & 126043 & -3.893 & 0.000 \\ \text { 2005:Q3 } & 0.035 & 0.023 & 126043 & 1.510 & 0.131 \\ \text { 2006:Q3 } & 0.061 & 0.023 & 126043 & 2.684 & 0.007 \\ \text { 2007:Q3 } & 0.013 & 0.022 & 126043 & 0.582 & 0.560 \\ \text { 2008:Q3 } & -0.164 & 0.022 & 126043 & -7.532 & 0.000 \\ \text { 2009:Q3 } & -0.061 & 0.022 & 126043 & -2.820 & 0.005 \\ \text { 2010:Q3 } & 0.092 & 0.021 & 126043 & 4.317 & 0.000 \\ \text { 2011:Q3 } & 0.046 & 0.022 & 126043 & 2.135 & 0.033 \\ \text { 2005:Q4 } & 0.078 & 0.023 & 126043 & 3.363 & 0.001 \\ \text { 2006:Q4 } & 0.053 & 0.023 & 126043 & 2.240 & 0.025 \\ \text { 2007:Q4 } & 0.066 & 0.022 & 126043 & 2.938 & 0.003 \\ \text { 2008:Q4 } & -0.142 & 0.023 & 126043 & -6.271 & 0.000 \\ \text { neph:In(Effort):In( } & -0.005 & 0.018 & 126043 & -0.272 & 0.786 \\ \text { Nets:In(Effort):In(E } & -0.113 & 0.032 & 126043 & -3.495 & 0.001 \\ \text { Ot:In(Effort): } \ln (E n ! & -0.113 & 0.017 & 126043 & -6.503 & 0.000 \\ \text { Pel:In(Effort):In(En } & -0.320 & 0.039 & 126043 & -8.208 & 0.000 \\ \text { Pots:In(Effort):In(E } & -0.083 & 0.025 & 126043 & -3.356 & 0.001 \\ \text { slope:In(Effort):In( } & -0.046 & 0.020 & 126043 & -2.361 & 0.018 \\ \text { SSC:In(Effort):In(Er } & -0.558 & 0.069 & 126043 & -8.046 & 0.000 \\ \text { TBB:In(Effort):In(E } & 0.013 & 0.029 & 126043 & 0.463 & 0.643\end{array}$

